Sergio Zañartu, s.j.

Facultad de Teología

Pontificia Universidad Católica de Chile

\title{
El logos en el De incarnatione Verbi de Atanasio. Una primera aproximación
}

\section{INTRODUCCIÓN}

El De incarnatione Verbi (DI) va precedido por el Contra Gentes (CG) (1), conformando ambos una unidad diferenciada. En ambos se dirige Atanasio a un amante de Cristo ( $\phi \iota \lambda \circ \chi \rho \iota \sigma \tau \varepsilon)$ (2), dando por supuesto que las citas bíblicas son probatorias para su lector (3). En ambos hace referencia a maestros cristianos, que tienen la correcta interpretación de la Escritura en la fe según Cristo (4). En CG I dice que va a exponer algunas pocas cosas de esta fe. El DI es llamado esbozo $(\chi \alpha \rho \alpha \kappa \tau \varepsilon \rho \alpha)$ breve, elemental, de la fe (5). Serían obras dirigidas principalmente a lectores cristianos para afirmar e ilustrar su fe contra las objeciones (6) de paganos y también explícitamente de judíos en el DI (7). Revisten un

(1) En el CG el texto utilizado es el de la edición de R. W. Thomson, Oxford 1971.

(2) CG 1; 47; DI 1, 11; 56, 4. Siendo las citas de este trabajo fundamentalmente del DI, estas, en adelante, aparecerán citadas directamente con los números de los párrafos correspondientes según la edición de Ch. Kannengiesser en Sources Chrétiennes, número 199, salvo cuando vayan precedidas de citas de CG en la misma nota. Agradezco al profesor Kannengiesser el que me haya introducido al estudio de este texto en un seminario de doctorado del Institut Catholique de Paris en 1966.

(3) Prácticamente no las usa en la parte en que polemiza contra los griegos en el DI. Según 56, 4-7, si el destinatario se aplica a las Escrituras, conocerá de manera más completa y clara la exactitud de lo dicho por Atanasio. Según CG 1, las Escrituras divinamente inspiradas son suficientes. Véase CG 45; DI 33, 9-13, etc.

(4) Cf. CG 1; DI 56, 9-12 (testigos de la divinidad de Cristo). Hace referencia a una tradición: comunica lo aprendido de otros. En CG 6 y 33 habla de la $\delta \iota \delta \alpha \sigma \kappa \alpha \lambda \iota \alpha$ eclesiástica; y de la $\delta\llcorner\delta \alpha \sigma \kappa \alpha \lambda \iota \alpha$ de Cristo en: CG 1; DI 10, 11s; 14, 36; 27, 20s; 28, 29s; 30, 26.31; 40, 66s; 48, 17s; $49,26-28.32 \mathrm{~s} ; 50,6 ; 51,4 \mathrm{~s} .31 \mathrm{~s} ; 52,13 \mathrm{~s} ; 53,22 ; 55,10 \mathrm{~s} .20$.

(5) 56, 1-3. Esto no quita que para mostrar lo razonable de la fe vaya presentando, en la discusión sobre


bastantes páginas 'dialogales' y muchas preguntas.

(6) Puede verse, p. e. DI 25, 1-3.

(7) Cf. p. e. CG 1; DI 1, 14-15. Y la aparente bajeza del Logos en la Encarnación contribuirá a una piedad mayor y más plena (DI, 1, 15-17). 
fuerte carácter apologético (8). Refutadas las objeciones, resplandecerá la verdad por sí misma (9).

En ellas nuestro autor afirma claramente la divinidad del Logos, pero no aparece directamente el problema arriano y los herejes nominados son los dualistas (10). Por eso diría que son más bien del comienzo de la actividad literaria de Atanasio, aunque pudieran haber sido retocadas después para su 'publicación' (11).

El CG trata del culto a Dios y de la verdad sobre el universo (I) (12). Es decir, refuta la idolatría y presenta al Dios creador del universo. La idolatría se fue expresando de diversos modos (IX-XI). Su origen es el libre pecado del hombre, por el que se introduce el mal en el mundo. Porque el hombre había sido creado a imagen y semejanza del Logos, imagen del Padre. Es decir, el hombre tenía la gracia de participar del Logos, y en el espejo puro de su alma inmortal podía contemplarlo y mediante él conocer al Padre. Pero el hombre abandonó la contemplación de Dios (13) y se forjó dioses inexistentes (II-VIII) (14). Atanasio ataca la idolatría por la inmoralidad del comportamiento de los dioses y por otros aspectos, como el ser dioses inanimados (XI-XIX). Impugna las imágenes que los representan y que son adoradas (XIX-XXII), la contradicción de su pluralidad ((XXIIIXXIV), la inmoralidad de algunos cultos (XXV-XXVI), el culto al cosmos y sus partes (XXVII-XXIX). Refutada la idolatría, resplandece el culto al único Dios, Creador y Señor de todo, Padre de Jesucristo nuestro salvador. Pero, aunque a menudo mencione a Jesucristo salvador (15), el CG no va a entrar ni en la Encar-

(8) Ch. Kannengiesser (Athanase d'Alexandrie, Sur l'incarnation du Verbe (Sources Chrétiennes, 199), p. 55) afirma al respecto: "L'auteur du DI veut donc surtout exhorter à croire davantage, présenter une catéchèse au sens large, centrée sur le mystère de l'Incarnation, polémique certes contre Juifs et païens, mais destinée à des chrétiens déjà solidement instruits dans leur foi et désireux de l'approfondir pour mieux la défendre contre leurs détracteurs".

(9) CG 1 (La fe es razonable). Véase CG 7.

(10) Salvo el oscuro pasaje de CG 30 sobre los que niegan el alma racional del hombre, reduciéndolo a

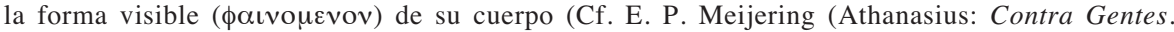
Introduction, Translation and Commentary (Philosophia Patrum, 7), Leiden 1984, op. cit., ad 1. c.). No hay ninguna referencia directa al docetismo (cf. DI 18,9s). Los dualistas mencionados son los marcionitas, según Meijering, ad num. 6, pp. 32-34.

(11) En este tan controvertido asunto, véase p. e. la breve introducción de Meijering (op. cit., 1-5). Ciertamente en DI, junto con la encarnación del Logos, Atanasio destaca mucho su divinidad. Pero este destacar la divinidad del Logos, no necesariamente es una reacción antiarriana. Porque Arrio puede ser una cristalización de tendencias anteriormente latentes, contra las que justamente podría ser la acentuación de Atanasio. El DI no presenta los ribetes antiarrianos que tendrá su polémica después. Esto sería muy de extrañar en el temperamento de Atanasio, si el DI fuera más tardío. Por lo demás, la divinidad del Logos calza muy bien con la profundidad del misterio de la Encarnación, que es objetado por griegos y judíos. Con todo, ¿la conciencia del triunfo arrasante del cristianismo puede ser de época tan temprana?

(12) La verdad sobre el universo es que es creación de Dios. Respecto a las influencias puede verse, $\mathrm{P}$. Th. Camelot, Athanase d'Alexandrie, Contre les païens et Sur l'incarnation du Verbe (SC, 18), 26-55; Meijering, op. cit. Puede verse también E. P. Meijering, Orthodoxy and Platonism in Athanasius. Synthesis or Antithesis?, Leiden, reprint 1974, pp. 5ss.

(13) Comenta Camelot (op. cit., 29): "L'homme cependant, attiré par les réalités sensibles, se laisse détourner des intelligibles, et tombe de l'unité dans la multiplicité des désirs corporels".

(14) “Anstatt den Logos zu erkennen, schufen sich die Menschen Götzen" (R. Schwager, Fluch und Sterblichkeit-Opfer und Unsterblichkeit. Zur Erlösungslehre des Athanasius, ZKT 103(1981)377399, p. 387).

(15) En CG 41 cita parcialmente Col 1, 15-18 a propósito de la creación. 
nación del Logos ni en su salvación, salvo en la introducción (16). Eso está reservado para el DI.

La segunda parte del CG comienza con el alma inmortal, que es camino para el conocimiento de Dios. Por eso el hombre, que había abandonado a Dios cayendo en la idolatría, es exhortado a la purificación para que su alma sea imagen del Logos en toda su pureza y así vuelva al conocimiento de Dios (XXIX-XXXIV). Pero como lo anterior no es suficiente a causa de los elementos extraños que lo impiden, el hombre puede conocer al único Dios creador a partir de la armonía de la creación visible, compuesta de contrarios. Porque es el Logos, por el que el Padre creó, quien conduce y gobierna el cosmos (XXXIV-XXXIX).

Ese único Dios creador es el Padre de Jesucristo salvador. Es muy hermoso y bueno, amante del hombre; quiere que todos existan; crea y mantiene el universo por su Logos bueno. Gobierna, pues, todo mediante su Sabiduría y su Logos. El Logos procede del Padre y es el único engendrado por él; es imagen exacta del Padre, distinto de la creación. Todo se sustenta en él. Es luz y vida del universo al que ha venido, y que él contiene, ordena y guía. Es providente. Así el universo canta al unísono, como las cuerdas de una lira. El Logos es el intérprete y mensajero del Padre (XL-XLV). En los números XLV-XLVI se agregan citas de la Escritura en referencia a lo anterior (17). Finalmente en el número XLVII añade, de paso, algunos otros atributos al Logos, coincidentes con los Jn, como puerta, pastor, camino, salvador para todos, mateniéndose siempre en lo creacional (18). Para terminar, igual que el final del DI, alude, en tono exhortativo, al juicio final (19). Así, en CG, centrado en el conocimiento de Dios, Atanasio ha refutado la idolatría y presentado al Dios que creó y gobierna el universo, mediante su Logos divino y unigénito (20).

Aunque el DI necesariamente tenga que tocar muchos de los puntos recién enumerados en el $\mathrm{CG}$, lo hará ahora en forma muy breve, porque está centrado en justificar y defender la Encarnación (21) salvadora del Logos contra griegos y judíos. Así, aunque comienza por la creación (y el Salvador va a ser el Creador), no se detendrá mucho en el pecado (22), sino que pasará a mostrarnos sus consecuencias,

(16) La introducción, en ese sentido, sería común a las dos obras. Así en el número I de CG, además de mencionar la enseñanza de Cristo y la fe en él, habla nuestro autor, a propósito de las burlas de los griegos, de la cruz salvadora y su victoria, que ha llenado el mundo del conocimiento de Dios. A esto Atanasio no se volverá a referir hasta el DI, lo que comprueba la unidad de los dos libros.

(17) ¿Tiene en cuenta, en esto, a los adversarios judíos, que se basan también en la Escritura? Cf. CG

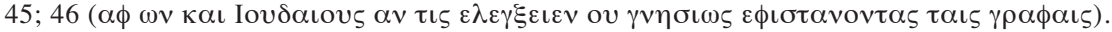

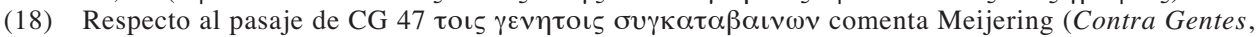
151): "All this refers to Christ's revelation of God in creation". Pero yo diría que en 41 de alguna forma está implicada la Encarnación.

(19) Pero en el DI será un juicio por las obras mediante el cuerpo en la manifestación, esta vez gloriosa, de Cristo.

(20) Cf. p. e. CG 40. El mismo Atanasio, al comenzar el DI resume así el CG: "Suficientemente en lo que precede hemos explicado en detalle algunos puntos de entre muchos: el error de los gentiles sobre los ídolos y su temor supersticioso de ellos; cómo se produjo al inicio la invención de ellos, ya que los hombres a partir de su mal proceder se imaginaron el culto a los ídolos. Pero también, por gracia de Dios, hemos señalado algunas cosas sobre la divinidad del Logos del Padre, su providencia y su poder respecto al universo, y que el buen Padre por él ordena todo, y que todo es movido por él y en él vivificado" (DI, 1, 1-10).

(21) Cf. p. e. $1,12-15 ; 56,1-3$.

(22) Y menos, en el origen del mal. 
las que provocan la venida del Logos. El DI se extiende largamente sobre las causas de la Encarnación: victoria sobre la muerte y corrupción, restablecimiento de la imagen y correspondientemente del conocimiento de Dios por sus obras. Se detendrá en las obras de Cristo en su vida y en su victoria actual. A este propósito nombrará la derrota de la idolatría, sin entrar aquí a refutarla en sí misma, y junto con ella irán los oráculos, magia, demonios, sabiduría de los griegos. Las pruebas contra los judíos serán a partir de las Escrituras, porque Cristo es el único que las realiza. En cambio, ha cesado el templo y el reino judío. Es decir, en DI la historia incide fuertemente en la confrontación con griegos y judíos. CG y DI, por tanto, son obras complementarias y así conforman una unidad diferenciada (23). Por eso, en CG 1 se enuncian temas que se retomarán y concluirán en DI, como la cruz y salvación.

Pasemos ahora a nuestra obra, el DI. Su plan, a grandes rasgos, sería el siguiente. Para hablar de las causas de la Encarnación (24) por bondad de Dios, se ve obligado a hacer una introducción sobre la creación y el pecado del hombre (25). Solo el Creador podía recrearlo, y como la muerte y corrupción estaba instalada en el interior del hombre, el Logos tenía que hacerse hombre para morir y derrotar la muerte, pagando nuestro rescate y devolviéndonos la incorruptibilidad en la resurrección. Esta es la primera causa de la que trata hasta el número $\mathrm{X}$ inclusive. La segunda causa, que enumera con cierta extensión, es la reconstitución de la imagen de Dios en el hombre. Por eso viene el mismo Logos, que es la imagen de Dios, modelo para el hombre. Por supuesto que la restauración supone la destrucción de la muerte. La imagen, que equivale a ser racionales participando en el Logos, va junto con el conocimiento de Dios. En esa imagen, como se dijo en el CG, podemos conocer al Logos y por el Logos al Padre. Pero el tema del conocimiento es más vasto: se puede conocer al Logos y a Dios por la creación, por la ley y los profetas, por las obras visibles de Cristo. Los números XI-XIX tratan principalmente de esto.

Siguiendo el tema de las obras de Cristo, Atanasio se detiene en la muerte, cruz y resurrección (XX-XXVI) para pasar a sus efectos, obras actuales, que muestran que está vivo y es Dios (XXVII-XXXII). Después de refutar a los judíos con las profecías y su cumplimiento (XXXIII-XL), enfrenta la risa de los griegos. Pudo y

(23) En el DI hace referencia a su obra anterior, a lo dicho antes, p. e.: 1, 1-10 (y prosigue $\kappa \alpha \tau \alpha$ $\alpha \kappa o \lambda$ ov $\theta(\alpha v) .28 \mathrm{~s} ; 4,17 ; 11,33 \mathrm{~s} .37$. En el DI se explaya sobre la actual victoria contra la idolatría, lo que complementa lo dicho contra esta en el CG. Cf. E. P. Meijering, Struktur und Zusammenhang des apologetischen Werkes von Athanasius, VC 45(1991)313-326. "Hiermit ist unmissverständlich die Hauptabsicht des zweiten Teiles genannt worden, nämlich zu zeigen, dass Gott der Erlöser kein anderer als Gott der Schöpfer ist” (ib., 314). Consigna así las principales diferencias de las obras: "Andererseits sieht man aber auch klare Unterschiede oder sogar Widersprüche, so vor allem darin, dass die Sünde in $C G$ anscheinend nur eine Besudelung der menschlichen Seele ist, die der Mensch selbst reinigen kann, während die Sicht in DI viel pessimistischer ist. Dort wird gesagt, dass nur die Inkarnation des Wortes den vom Sündenfall verursachten Tod überwinden kann. In DI (3) wird von Anfang an die Schwäche der meschenlichen Natur betont. $C G$ bietet dagegen ein optimistischeres Bild, insbesondere in den Kapiteln 30-34, in denen die Möglichkeit der Kontemplation des Göttlichen gelehrt wird. Mit dieser Vorstellung wird in DI gebrochen. Athanasius hat nach einer 'flirtation' mit dem Neoplatonismus in $C G$ diesen später gänzlich verworfen" (ib., 313)

(24) Ya en la Introducción dice que los judíos la calumnian y los griegos se ríen de ella, pero nosotros la adoramos. La sabiduría humana la ridiculiza como inconveniente e imposible, pero Dios con su poder la muestra divina. La cruz triunfa de la incredulidad (cf. 1, 14-28).

(25) El tener que volver a esto, muestra cierta independencia del DI respecto al CG. 
era necesario que se encarnara. Además de los milagros de Jesús, muestra nuestro autor la gran victoria actual y universal de Cristo contra el paganismo y el maravilloso cambio de costumbres, lo que confirma que es Dios y vino a divinizarnos (XLI-LV). Concluye con un llamado a la purificación ante la vuelta de Cristo para el juicio (LVI-LVII). Lo que acabo de decir puede servir de una cierta primera presentación o esbozo de la estructura de la obra, pero deja innumerables cosas afuera, y, además, en Atanasio los temas a ratos se entrelazan o repiten (26).

Lo que pretendo en este trabajo es solo una primera y modesta aproximación al tema del Logos, en una presentación general. Por eso parto con la relación al Padre (I), pasando después a la relación con la creación (II). Entonces, como introducción a lo que viene, me fijo, en general, en la relación con el cuerpo, en cómo se dice la Encarnación (III), para entrar a continuación en el tema central, que es el de las dos causas de la Encarnación y el modo en que esta realiza la salvación. Siguiendo el tema del conocimiento de Dios a propósito de la restauración del hombre según la imagen e introducido por el cumplimiento de las profecías, paso a las obras de Cristo especialmente en la actualidad (27). Así quedará clara la divinidad de Cristo y nuestra divinización (IV). Finalmente concluyo. Sobre todo a partir de la parte III, sigo un poco el ritmo de la misma obra de Atanasio, con sus repeticiones.

Esta 'explicación' o desarrollo, un poco de conjunto, obviamente va a perder muchas de las riquezas y acentuaciones de la obra de Atanasio, al presentar de otra forma su discurso y encasillarlo para exponer su pensamiento. Por eso solo intento una 'aproximación parcial', como todas, pero que pueda ayudar a comprenderlo mejor. El presente trabajo, aunque tome en consideración el Contra Gentes, está dedicado al De Incarnatione Verbi, porque este último también tiene en sí una estructura que engloba una totalidad (de hecho vuelve a atacar la idolatría, a hablar del Logos creador y del conocimiento de Dios, etc.), porque ofrece en sí suficientes claves de interpretación, porque su historia se presta a eso (28), en cuanto algunas ediciones lo editan o comentan aparte. Este trabajo es primariamente sobre el texto griego, editado por Ch. Kannengieser (29), sin por eso menospreciar los comentarios y bibliografía. Como todo el trabajo pretende ser lo más textual posible, las citas explícitas no suelen ir entre comillas ni con letra especial.

\section{EL LOGOS DEL PADRE}

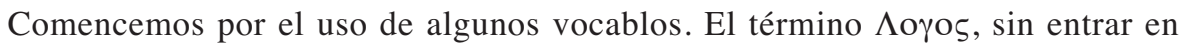
las variantes textuales, aparecería aplicado al Hijo en el DI unas 133 veces, de las

(26) Por lo demás, Atanasio, como el mismo lo declara en DI 20, 22-28, no temerá repetir.

(27) La perspectiva de la resurrección final y juicio escatológico completan la visión del actuar de Cristo en el DI.

(28) Cf. el título cuasi unánime de la tradición manuscrista (véase Kannengiesser al 1. c.) y las ediciones y comentarios aparte que tiene la obra.

(29) Por lo demás es el que trae el TLG, que utilizo como un instrumento, p. e. para el número de veces en que está cada palabra, etc. En las influencias (véase p. e. Kannengiesser, Athanase, Sur l'incarnation $d u$ Verbe) no suelo entrar en este trabajo que solo es una primera aproximación de conjunto, aunque a veces remito a bibliografía para aclaración o confirmación de algún punto. 
que unas 51 veces se dice que es Logos de Dios (30), 13 que es Logos del Padre (31) y 16 que es o $\Theta \varepsilon$ os $\Lambda$ oros (32).

En cambio, el Hijo es llamado Yıos en relación al Padre solo 23 veces, aña-

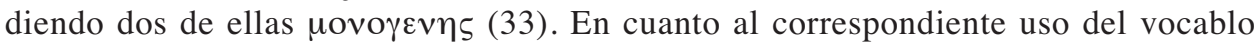
$\Pi \alpha \tau \eta \rho$, este es aplicado al Padre (34) 69 veces y prácticamente va siempre con una referencia inmediata al Hijo (o Logos, etc.). Por un lado, este П $\alpha \tau \eta \rho$ crea y ordena el universo mediante el Hijo (al menos 4 veces) (35); por otro lado, el Hijo conduce todo al Padre (36). El Padre es el $\pi \alpha v \alpha \gamma \alpha \theta$ os (37), Dios demiurgo (38), amante del

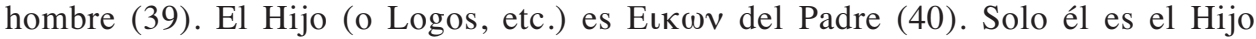
unigénito y verdadero del Padre (41). En 32, 31s, afirma nuestro autor que el Salva-



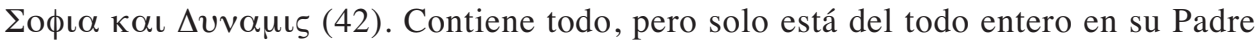
(43). Atanasio insiste mucho (unas 22 veces) en que es el que enseña, da a conocer al Padre o en el cual el Padre es conocido mediante él. Finalmente, mediante él se adora al Padre (44). En la despedida se refiere a los que aman al Dios y Padre en Cristo Jesús nuestro Señor, por el cual y con el cual, para el Padre con el Hijo en el Espíritu Santo, honra, poder y gloria por los siglos de los siglos (45). Esta fórmula hace aparecer por primera y única vez al Espíritu Santo (46).

Sintetizando lo dicho a propósito del vocablo 'Padre', todo viene del Padre por el Logos o Hijo, quien dirige todo a él. Conocimiento y adoración al Padre son por medio del Hijo (que es, por lo demás, Señor y Dios). Pero en DI Atanasio no dice

(30) Esto incluye los usos de $\alpha v \tau o v$, etc., cuando el sujeto es Dios. También cuento aquí los $\theta \varepsilon$ ov

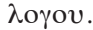

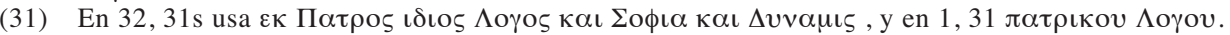

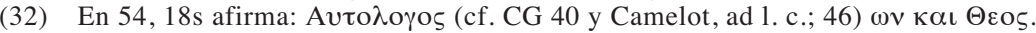

(33) 16 veces es nombrado 'Hijo de Dios; y unas 5 aparece como Hijo del Padre. En 17, 29s dice

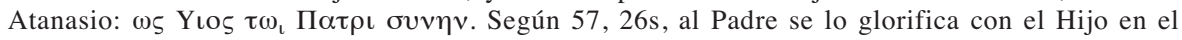
Espíritu Santo.

(34) Al menos 20 veces indica explícitamente que es su Padre.

(35) Y por él también salva (cf. 1,41s).

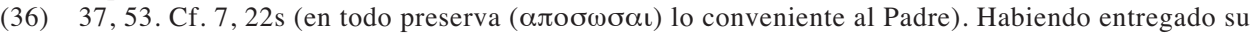
cuerpo a la muerte por todos (lo) presenta al Padre $(8,31$ s). Es nuestro embajador ante el Padre $(7,25 \mathrm{~s})$.

(37) 10, 7. Cf. 1, 8. Dios, Padre de la verdad (7, 5).

(38) $12,20 \mathrm{~s}$

(39) 1,34 (respecto a la Encarnación).

(40) $13,35.41 ; 14,7 ; 20,7$. Cf. 3, 24; 11, 17s (Jesucristo).19;13, 27.30 (imagen de Dios). Siempre en referencia al hombre creado a imagen de Dios. Según Ch. Kannengiesser, “aussi le Logos n'est-il Image pour lui qu'en référence à cette universelle économie salutaire qui englobe la création originelle et la rédemption" (Le Verbe de Dieu selon Athanase d'Alexandrie, LavalThPh 45 (1989) 229-242, p. 236)

(41) 20, 11s. Hijo amado $(52,2 \mathrm{~s})$.

(42) Cf. 19, 10; 48, 48s. Respecto a que el Logos es $\Sigma$ oфı $\alpha$ de Dios, véase 16, 6s; 31, 28s; 46, 17; respecto a que es $\Delta v v \alpha \mu \iota \varsigma$ de Dios, véase 18,$20 ; 21,30.36 ; 46,11 ; 51,15 ; 55,40$ (cf. 8, 27; 55, 14). Estos usos de los vocablos siempre están en relación a nosotros.

(43) 17, 9-11. Cf. 8, 4s; 17, 27.29s. El está en el Padre y el Padre en él (18, 16s). Véase 17, 4s

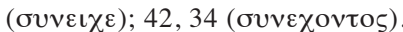

(44) 46, 37s; 51, 19s. Véase también, p. e. 40, 30-32.62s. Cf. 45, 35s

(45) $57,24-27$.

(46) Esta extrema parquedad sobre el Espíritu Santo se dará también en el Credo de Nicea. 
explícitamente que el Padre genere al Hijo (47). El Hijo o Logos siempre aparece mencionado en relación a la creación o encarnación redentora, aunque estando en el mundo, solo esté entero en el Padre, junto con quien se lo glorifica en la despedida, después de la referencia al juicio escatológico. En otras palabras, no hay una reflexión sobre la Trinidad inmanente, sino que el Padre por el Hijo está volcado al mundo (48). Y el nombre mayoritariamente empleado para el Hijo en el conjunto de

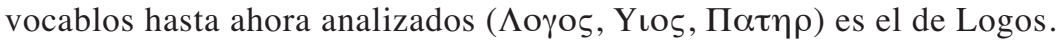

Del Hijo se dice que es 'Dios'. Examinemos un poco el término $\theta \varepsilon$ s. Cristo se hace conocer como Dios e Hijo de Dios (49). El es el Dios Logos que se encarna (50), que se manifiesta por sus obras, como las de la cruz (51); y borra la muerte que

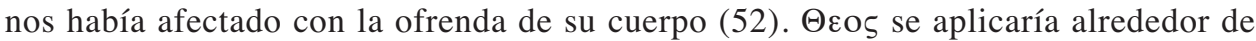

(47) Y pese a estar centrado en la Encarnación, una sola vez $(40,43 \mathrm{~s})$ hablará de envío $(\varepsilon \xi \alpha \pi \varepsilon \sigma \tau \varepsilon\llcorner\lambda \varepsilon)$ citando Salmo 106, 20 (LXX): "Envió a su Logos y los sanó".

(48) Kannengiesser (Athanase, Sur l'incarnation du Verbe, 72) se expresa así: "Cette relation intime de Père à Fils au sein de la divinité ne semble pas devoir être décrite par l'apologète. Celui-ci en énonce le principe pour affirmer à la fois l'unité d'action et la distinction de l'être personnel du Père et du Fils dès qu'entre en ligne de compte la relation fondamentale de l'homme à Dieu. C'est à partir de cette position dogmatique non élucidée qu'Athanase développera en $C G$ - $D I$ toutes ses considérations sur le rôle du Logos dans la création et la rédemption du genre humain. En fait, ce rapport Père-Image au sein de Dieu, tel qu'il est supposé par $C G$-DI, se ramène à des vues profondément traditionnelles. L'Image est unie au Père à la fois selon l'être et selon l'agir de ce dernier. Selon l'être du Père, elle nous en fournit l'intelligibilité; elle est pour nous sa représentation parfaite. Selon 1'agir du Père, 1'Image est puissance opérative; l'agir paternel se définit et s'accomplit en elle".

(49) 19, 27s; 53, 18-20 (el Salvador crucificado). Cf. 16, 6s.22s (Dios Logos); 18, 4s (Dios Logos, ordenando a la vez todo el universo); 18, 5s (Dios Logos).24s; 19, 17s (en la cruz); 30, 43s; 32, 23s; 33, 16-18; 45, 25s; 46, 22-24; 47, 19s (Dios de Dios verdadero, Dios Logos); 49, 29s (Dios Logos); 53, 16s; 55, 13s (poderoso Dios Logos). 36s (Dios Logos). 39s (Dios Logos y $\Delta v v \alpha \mu \iota \varsigma$ de Dios). 43s (Dios y verdadero Hijo unigénito de Dios, Logos).

Por sus obras corporales se lo conoce como el Logos de Dios en cuerpo (14, 45-47; y, mediante él, se conoce al Padre). Cf. 15, 24-36; 17, 38s; 18,11-13.17-21; 19, 7-16; 23, 14-17; 48, 47-53 (Hijo de Dios, Logos, Sabiduría y $\Delta v v \alpha \mu \iota \varsigma$ del Padre); 53, 31-33; 54, 6-13. Véase 30, 47s; 43, 33-37; 50, 40s .

(50) 10, 24s. Cf. 39, 3s; 46, 2s. Véase 38, 24s (Dios); 40, 36 (Dios).42s (Dios); 42, 6-10 (Dios Logos);

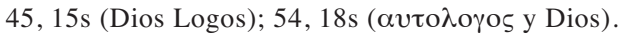

Es el incorporal, incorruptible e inmaterial Logos de Dios que viene a nuestra región $(8,1 \mathrm{~s})$. Es el incorruptible Hijo de Dios que revistió a todos de incorruptibilidad por la promesa de resurreción (cf. 9, 15-17). Es el Logos de Dios que viene por sí mismo, como imagen del Padre para recrear la imagen (cf. 13, 34-36). Es el verdadero Hijo de Dios, su propio Logos, Sabiduría y $\Delta v v \alpha \mu \iota \varsigma$, que en los últimos tiempos tomó un cuerpo para salvación de todos (32, 31-33). Es el Logos de Dios, incorporal por naturaleza, que se manifiesta en un cuerpo por nosotros y padece (38, 1214). Es la $\Delta v v \alpha \mu \iota \varsigma$ de Dios, el Logos, $\Delta \varepsilon \sigma \pi 0 \tau \eta \varsigma$ de todo, quien por la debilidad de los hombres apareció sobre la tierra (cf. 46, 11-13); la verdadera Sabiduría de Dios que se automanifestó (46, $17 \mathrm{~s})$.


34 (cuerpo incorruptible por la venida e inhabitación del Logos de Dios); 21, 29-31 y 35-37

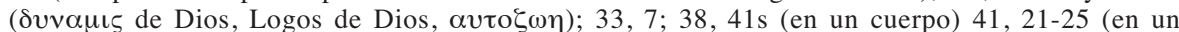
hombre); 55, 17s (viniendo la divina epifanía del Logos de Dios).34s

(51) $19,20 \mathrm{~s}$

(52) 10, 7-10 (por su medio había sido hecho el género humano). Es el Logos de Dios, superior a todo (véase también 7,23s), que ofreciendo su templo e instrumento corpóreo como rescate por todos, con razón pagaba la deuda con su muerte $(9,12-15)$. Su cuerpo revistió al incorporal Logos de Dios (la vida); en él desaparece la corrupción (cf. 44, 56-60). El Logos de Dios tomó un cuerpo y usó un instrumento humano para vivificar el cuerpo y para mostrarse por sus obras (cf. 45, 1-6). 
31 veces al Hijo (53) y unas 96 veces al Padre a propósito de la creación o de la salvación del hombre, más otras 76 en que 'Dios' va en genitivo acompañando la

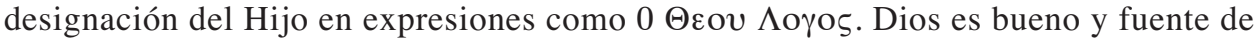
la bondad (54). Esta es como la gran característica de Dios. Considerando, pues, el vocablo $\Theta \varepsilon \varepsilon_{\varsigma}$, nos resalta la afirmación de la 'divinidad' del Logos y de Cristo, el Logos en un cuerpo.

Pero pasemos a otras consideraciones más allá del uso de estos vocablos. Atanasio no se detiene mayormente a probar la existencia de Dios en esta obra. Frente a idólatras y judíos afirma, a partir de la enseñanza divina y de la fe cristiana, contra epicúreos (55), Platón (56) y herejes dualistas (57), que Dios creó el universo de la nada mediante su Logos (58). Gran argumento es el orden del mundo (59). Varias veces repetirá que al Logos lo podemos conocer por el orden del universo y mediante él al Padre. Parece dar por supuesto que Dios tiene un Logos distinto de él (por el que crea y actúa), aunque insistiendo en su divinidad (60). Por eso tampoco se detiene a argumentar contra los griegos que pudieren negar del todo la existencia de un Logos (61). Contra los judíos, que a nuestro juicio podrían ser más sensibles en esto, argüirá desde las profecías y su cumplimiento, sin plantear el problema (62). Esta obviedad de la existencia del Logos es confirmada por el texto de CG 40: dudar de la existencia del Logos sería estar loco, porque el universo subsiste por el Logos y Sabiduría de Dios (63). Diríamos que mirando desde el orden del mundo le parece inconcebible un Dios sin Logos y Sabiduría. ¿Es que en el fondo, partiendo de un cosmos múltiple, a Atanasio le parece impensable que ese Logos, que es creador y ordenador, no sea distinto de Dios en cierto aspecto? Cuando en CG 46

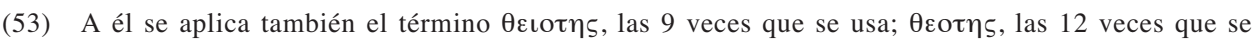
usa, salvo en 53, 30s; y 15 veces el adjetivo $\theta \varepsilon \iota s: 11$ veces califica su manifestación y 4 otros aspectos de Cristo. De 13 veces que se usa el verbo $\pi \rho \circ \sigma \kappa v v \varepsilon \iota v, 7$ están en referencia al Logos.

(54) 3, 15s. Cf. 10, 7; CG 40; 41; 46 .

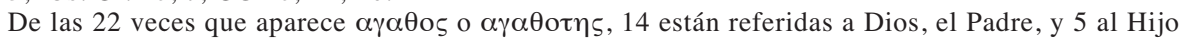
(incluyendo 43, 22s). Dos veces la bondad del Padre va junto con su filantropía. De 11 veces que se usa este último vocablo o sus conrrespondientes adjetivo, verbo y adverbio, 9 están referidos al Logos. Y las 11, salvo una, están en relación directa a la encarnación y redención. En 20, 23 usa

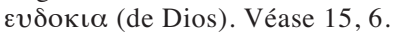

Dios tiene el dominio del universo $(11,1)$; es invisible por naturaleza $(54,1 \mathrm{~s})$. Dios es el que es

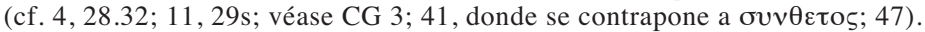

(55) El ordenamiento del mundo muestra que hay una causa que hizo y dispuso todo. Este no se debe al azar y espontaneidad. Existe una $\pi \rho 0 v o \iota \alpha(2,3-18)$.

(56) Según ellos, Dios es un simple artesano que utiliza una materia preexistente e increada. Atanasio dirá que eso no es creación sino debilidad (2, 18-37).

(57) Según ellos el demiurgo es diferente del Padre de Jesucristo, lo que choca con los dichos de Jesús y la visión de conjunto de Jn 1, 3 (2,37-51). También en CG 6s Atanasio los refuta por los dichos de Jesús, pero muestra a la vez lo contradictorio que sería poner dos principios antagónicos. El mal no surgió de Dios, ni existe desde el comienzo, ni es substancia. Por lo demás, si la creación fuera obra del Dios malo, ¿qué obra entonces nos daría a conocer la existencia del Dios bueno? Gregorio de Nisa, en la Oratio Catechetica número V al VIII se detendrá más largamente en el origen del mal, que él definirá como ausencia del bien, de la virtud.

(58) 3,1-19.

(59) 2, 15-18, etc. Argumento largamente desplegado en el CG.

(60) Según DI 1, 6-8, de ella ya trató en CG.

(61) 41, 10-12. Otros podrían admitirlo como Logos del Padre, creador y providente (cf. 41, 12-18).

(62) Lo que más se acercaría, es 40, 41-46.

(63) Véase CG 47. 
trae las citas del A.T. respecto a la creación, pone el texto del Salmo 32, 6 (LXX) y arguye desde el "hagamos al hombre", donde Dios conversa con alguien cercano. Porque cuando Dios creó el cielo y la tierra, su Sabiduría estaba junto a él $(\operatorname{Pr} 8,27)$. Concluye ahí con la fe neotestamentaria: Todo fue creado por él y para él. Más tarde, Gregorio de Nisa en su Gran Catequesis partirá probando rápidamente la existencia de Dios por la hábil y sabia disposición del universo (64) y, aunque todos conceden que Dios tiene Logos, mostrará que este es distinto del Padre para no caer en conceptos judaicos (65).

Resumamos lo dicho hasta ahora, sobre todo lo indicado por los textos de los vocablos vistos respecto al Logos y el Padre. El Logos del Dios verdadero (66), hijo unigénito y amado del Padre bueno, verdaderamente es Dios. El Padre crea y ordena el universo mediante el Logos y este da a conocer al Padre (67) y conduce todo hacia el Padre. Este verdadero Hijo de Dios es la imagen del Padre, su Logos ( $\varepsilon \kappa$ $\Pi \alpha \tau \rho \circ \varsigma)$, Sabiduría y Poder ( $\Delta v v \alpha \mu \iota \varsigma)$. Entre el Hijo y el Padre hay un mutuo estar en el otro, según cita de Jn 10, 38 (68). Solo en el Padre está enteramente el Hijo. Al final de la obra se glorifica al Padre junto con el Hijo. Diríamos que el Padre está volcado al mundo por su Logos. Cristo se manifiesta como Dios por sus obras. Es el Logos incorporal (69) (inmaterial (70), incorruptible (71), la vida misma (72) que se encarna, Logos en un cuerpo mortal. Atanasio da por supuesto la existencia de Dios y su Logos.

Como en el CG ya había tratado del Logos (y la creación), Atanasio ya no tiene en el DI números sobre el Logos como el del final del número 46 del CG: "Sus sagrados discípulos enseñan que todo fue creado por medio de él y para él y que, siendo vástago bueno del Bueno, y verdadero Hijo, es la $\Delta v v \alpha \mu \iota \varsigma$ del Padre, Sabiduría y Logos, no siéndolo por participación..., sino que es la misma Sabiduría

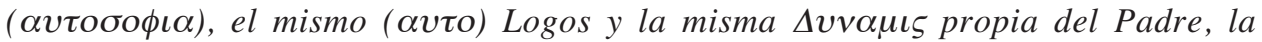
misma luz, la misma verdad, la misma justicia, la misma virtud, y ciertamente

(64) Prol. p. 6 lin. 17-21.

(65) I, 10, 26-12, 3 Según este autor (Oratio Catechetica, I, 8, 15s), aun los extraños a nuestra creencia conceden que Dios tiene Logos. Dedica los números I-IV a probar que ese Logos distinto y el Espíritu son divinos. Conocerá al Logos y al Espíritu subiendo anagógicamente desde lo nuestro a la naturaleza $v \pi \varepsilon \rho \kappa \varepsilon \iota \mu \varepsilon v \eta$ (II, 12, 4s). Respecto a los judíos utilizará el mismo Salmo 32, 6. Puede verse S. Zañartu, El Dios razonable de la Gran Catequesis de Gregorio de Nisa, Teología y Vida 45 (2004) 564-604, pp. 567-570.

(66) Padre de la verdad. Verdad se aplicaría al Padre unas 9 veces, en cambio al Hijo alrededor de 16. El es la $\alpha \lambda \eta \theta \varepsilon \iota \alpha$, que se hace presente sobre la tierra $(40,9 ; 47,23 \mathrm{~s})$. Respecto al concepto, puede verse R. Bernard, L'image de Dieu d'après saint Athanase (Théologie 25), Paris 1952, p. 30s.

(67) A través del Logos se lo conoce.

(68) $18,16 \mathrm{~s}$.

(69) Cuatro veces es dicho del Hijo y una $(11,6)$ de Dios. En este mismo pasaje usa $\alpha \gamma \varepsilon v v \eta \tau o v$

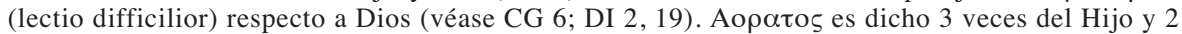
de Dios o del Padre. Véase $\alpha \phi \alpha v \eta$ en 16, 25. Cf. 32, 2s.

(70) 8,2 .

(71) Cuatro veces es dicho directamente del Logos. Otras 7 veces del cuerpo de Cristo. A $\theta \alpha v \alpha \tau o \varsigma$ se aplica solo 2 veces directamente al Logos. Este término 4 veces es usado respecto al cuerpo resucitado. En 54, 18 es calificado como $\alpha \pi \alpha \theta \eta \varsigma$ (cf. 54, 20). Esto último es dicho también de su cuerpo resucitado en $26,16 \mathrm{~s}$.

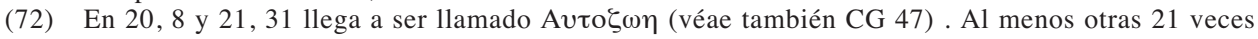
aparecerá identificado con la $\zeta \omega \eta$. Este substantivo no se aplica al Padre. El Hijo es el que nos restaura y vence a la muerte. 
impronta, resplandor e imagen. Para sintetizar, es el fruto perfecto del Padre y único Hijo, imagen exacta ( $\alpha \pi \alpha \rho \alpha \lambda \lambda \alpha \kappa \tau o \varsigma)$ del Padre”. Respecto al DI, el CG presenta al Padre $\pi \alpha v \alpha \gamma \iota$ s como más trascendente al ponerlo $v \pi \varepsilon \rho \varepsilon \kappa \varepsilon \iota v \alpha \pi \alpha \sigma \eta \varsigma$

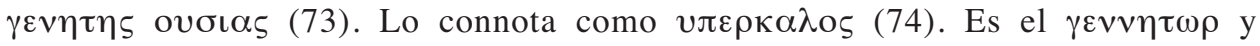

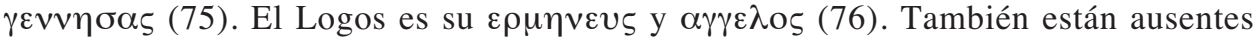
en el DI algunos de los atributos creacionales del Logos en CG 47. Del mutuo estar

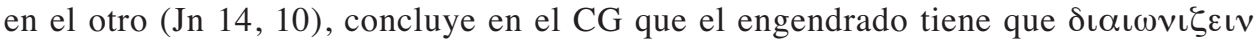
con el Padre (77). Todo esto confirma lo ya dicho que ambos son escritos complementarios, en el sentido de que el DI (sobre la Encarnación) supone el creacional y anti-idolátrico CG, aunque lo repite en forma más abreviada, conforme a su tema.

\section{EL LOGOS Y LA CREACIÓN (78)}

Atanasio comienza diciendo, respecto a la manifestación corporal del Logos (tema central), que conviene hablar primero de la creación del universo y de su

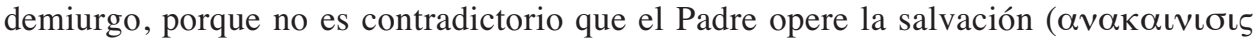
de la creación), mediante el mismo por quien la creó. Así se verá también que el Logos no ha llevado un cuerpo humano por necesidad de su naturaleza, sino por filantropía y bondad de su Padre, Para esto va a hacer memoria de lo antes dicho en el CG (79).

Contra los epicúreos concluye, por el orden del cosmos, que Dios dispuso e hizo el universo (80). Contra el Dios artesano ( $\tau \varepsilon \chi \nu \iota \tau \eta \varsigma)$ de Platón y otros, arguye

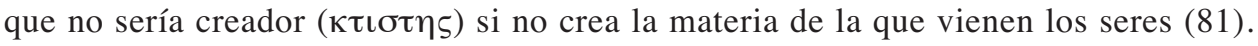
Después de rechazar, con textos del N. T., un demiurgo distinto del Padre de Jesucristo y de resumir, confiesa la fe bíblica y cristiana: Dios hizo el universo de la nada mediante su propio Logos, nuestro Señor Jesucristo, porque es la fuente de la bondad (no es celoso) (82).

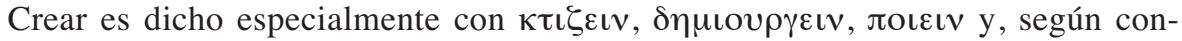

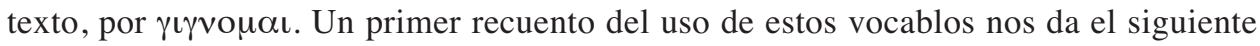

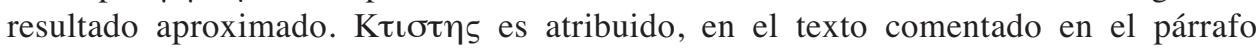
anterior, dos veces a Dios, y después será atribuido dos veces a Cristo (83), Creador y Señor. El verbo $\kappa \tau \iota \zeta \varepsilon \iota v$ es usado 8 veces en voz activa, siendo siempre Dios su sujeto correspondiente; en cambio, $\alpha v \alpha \tau \iota \xi \varepsilon \iota v$ es usado 3 veces teniendo al Logos, que es el

(73) 40. Cf. CG 2; 35.

(74) CG 2; 41.

(75) CG 47.

(76) CG 45. Y añade el texto de Jn 14, 9. Como en la palabra humana vemos significado al vous, así en el poder del Logos llegamos a la idea de su buen Padre.

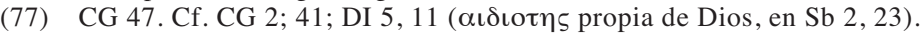

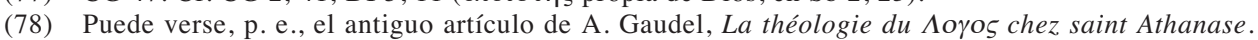
Une synthèse christologique à la veille de l'arianisme, RevSR 11 (1931) 1-26, pp. 1-14.

(79) $1,28-43$.

(80) 2, 15-18.

(81) 2, 32-37. No poder crear sin materia sería atribuir debilidad a Dios. Atanasio está suponiendo un buen concepto de Dios.

(82) $2,37-3,19$.

(83) $18,43-45$. Cf. $45,21$. 
único que puede recrear (84), por sujeto. El substantivo $\kappa \tau \iota \sigma \iota \varsigma$ aparece 34 veces (85). En estas se nos dice, entre otras cosas, que por las creaturas se puede conocer a Dios (86), y al Logos y Cristo (87), Señor de la creación y demiurgo (88); que el Logos está presente en toda la creación, no participando de ella sino que ella participa de su poder (89); que Cristo, el rey de la creación (90), libera y rescata todo (91).

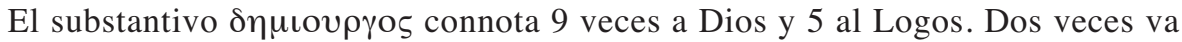

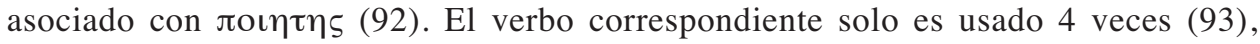
una de las cuales tiene como sujeto al Logos. La renovación de la creación es realizada por el mismo Logos que la creó en el comienzo (94). El Padre realiza la salvación de ella en aquel mismo, mediante el cual la creó (95).

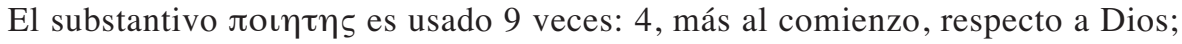
y después, el resto respecto al Logos (96). El verbo Joıєıv (en voz activa) referido a la creación primera, tiene aproximadamente unas 22 veces por sujeto a Dios (97) y unas 3 veces al Logos. En 7 de ellas se explicita que la creación es de la nada. Así, desde la nada, mediante el Logos, Dios ha creado y traído a la existencia a todas las cosas, que de ninguna manera eran (98).

De cerca de 39 veces en que $\gamma \iota \gamma v o \mu \alpha \iota$ se emplearía en sentido creacional, en unas 15 el crear estaría atribuido más directamente a Dios, y en unas 9 al Logos.

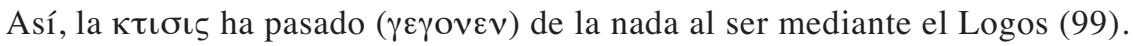

(84) Siendo la imagen del Padre (13, 35s; 20, 5-7).

(85) Una vez es usado $\kappa \tau \iota \sigma \mu \alpha$ y otra $\kappa \tau \iota \sigma \theta \varepsilon v$.

(86) Al menos unas 5 veces.

(87) Al menos unas 9 veces. Así, por la armonía se puede conocer al Logos $\rceil \gamma \varepsilon \mu \omega v(12,14 s)$, quien mueve todas las cosas en la creación, y mediante su providencia respecto a ellas hace conocer al Padre (cf. 12, 14-18; 14, 32-34). A través de la providencia del Salvador en la creación se debería haber conocido su divinidad (cf. 19, 2-4). Véase 53, 29-31 (por la potencia).

(88) Los fenómenos cósmicos acontecidos en la cruz, muestran que es el $\delta \varepsilon \sigma \tau o \tau \eta \varsigma$ de la creación (cf 19, 16-20). Toda la creación testificaba la presencia de su demiurgo $(26,6 \mathrm{~s})$.

(89) Cf. 17, 4-10 (contiene el universo sin ser contenido por este). 12s.32s; 43, 37-39; 45, 26-31 (entró en contacto con todas las partes de la creación).

(90) 37, 39s.

(91) $37,56$.

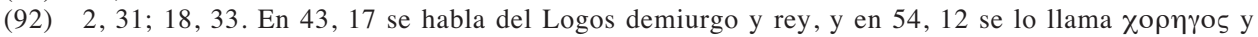
demiurgo. Respecto a Cristo como rey, cf. p. e. 9, 25s; 16, 27s (va con $\eta \gamma \varepsilon \mu \omega v$ ); 37, 39s (de la creación); 51, 3s. Véase 36,1-3.8-10; 40, 32s; 41, 15s; 55, 28s.31. El Logos es el $\rceil \gamma \varepsilon \mu \omega v$ del

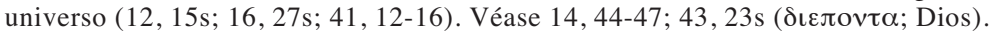

(93) La $\delta \eta \mu o v \rho \gamma \iota \alpha$ de Dios aparece otras dos veces. Para esta creación de la nada, bastaba con quererlo; en cambio, para curar y salvar lo ya existente será necesario que el Logos venga por lo semejante (el cuerpo) (44,1-21).

(94) 1, 38-43. E. Bellini afirma: "L'opera redentrice di Cristo concepita come un rinnovamento ( $\alpha v \alpha \kappa \alpha \iota v \iota \sigma \iota \zeta)$, nel senso forte di nuova creazione, è un tema caro ad Atanasio. Atanasio se ne serve per dimostrare la divinità di Cristo e la continuità tra la creazione e la redenzione" (Traduzione introduzione e note, Atanasio, L'Incarnazione del Verbo (Collana di Testi Patristici, 2), Roma 1993, $3^{\mathrm{a}}$ ed, n 6).

(95) 1, 38-43. Véase 41, 12-14 (en él, el Padre ha producido la creación).

(96) Y a Cristo en concreto. Lo mismo puede decirse de muchas de las otras citas, que he connotado como del Logos.

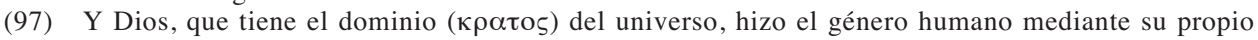
$\log 0$ (11, 1s).

(98) $3,5-7$.

(99) 42,14 s. 8 veces se hace referencia a la nada en el uso de este verbo. Según cita de Hb 2, 10, 'para el y por él' está aplicado a Dios $(10,25 \mathrm{~s})$. 
Este rápido recuento de los principales vocablos nos muestra lo contundente que es la presencia de la creación en este libro centrado en la Encarnación; y lo es porque trata de las causas de la Encarnación. Y aunque en el número 3 y parte del 4 trate de la creación, el vocabulario muestra que en el resto vuelve Atanasio continuamente a este tema. Porque la Encarnación redentora va íntimamente entrelazada con el tema de la creación: se trata de restaurarla, de recrearla, lo que solo el Creador puede hacer (100). También queda muy claro que nuestro autor excluye el concepto de la materia preexistente: la creación es de la nada. Evidentemente, Dios es el que crea mediante el Logos, pero si nos fijamos en los sujetos de las oraciones, muchas veces aparecerá en el primer plano el Logos como el Creador. Con todo, mucho más veces se habla de Dios Creador, y muy a menudo sin mención del Logos. Es de notar el uso diferente de los vocablos $\tau \iota \xi \varepsilon \iota v$ y $\alpha v \alpha \tau \iota \xi \varepsilon \iota v$. Cristo va a ser el $\Delta \varepsilon \sigma \pi 0 \tau \eta \varsigma$ del universo (101), también de los demonios (102).

El Logos no abandonó el universo después de crearlo, sino que lo ordena con armonía (103), lo conduce con su providencia ( $\pi \rho o v o \iota \alpha)$ (104), lo vivifica (105), ilumina (106) y mueve (107). Así la armonía de la creación da a conocer al Logos $\eta \gamma \varepsilon \mu o v \alpha$, quien con su providencia respecto a todo da a conocer al Padre, y mueve el universo para que, mediante él, todos conozcan a Dios (108). El Logos está presente en todo el universo. Ninguna parte del universo está vacía de él (109). Por supuesto que es Dios el que actúa por él. Así el Padre bueno con él organiza

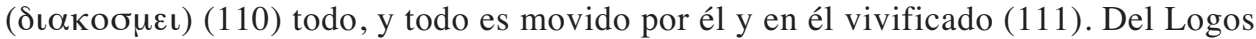
ya vimos que es el $\eta \gamma \varepsilon \mu \omega \nu, \chi о \rho \eta \gamma о \varsigma, \beta \alpha \sigma \iota \lambda \varepsilon v \varsigma$.

Por lo visto, se podría decir que el Logos, en esta obra, es presentado, en cierto sentido, como una especie de eslabón entre el Padre y la creación, porque el Padre crea y actúa por medio de él. El Logos, por un lado, está en la creación y en todas

(100) Schwager (op. cit, 392-395) insiste en que no se trata de un simple restaurar la promesa primitiva de inmortalidad sino que esto es llevado a un estado más perfecto que el originario.

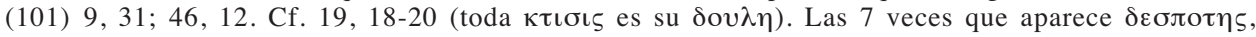
están referidas a Cristo. Como $\delta \varepsilon \sigma \pi о \tau \eta \varsigma$ anda sobre el mar, prueba de su $\delta \varepsilon \sigma \pi 0 \tau \varepsilon \iota \alpha$ universal $(18,45-47)$

(102) $45,16-18 ; 46,11 \mathrm{~s} ; 48,28-30$

(103) Cf. 12,14s. Con mucho mayor frecuencia usa este vocablo en CG.

(104) Las 15 veces en que se usa este vocablo, se refieres a la providencia universal del Logos, salvo 2 en que no se nombra al Logos y es opuesto al $\alpha v \tau o \mu \alpha \tau \omega \varsigma$ de los epicúreos. La Encarnación y los milagros de Jesús son parte de esta providencia universal (18, 47-51; 19, 1-7; 54, 10s). Su providencia universal va acompañada con los conceptos como ordenar, mover, conducir, reinar, iluminar, dar la vida y el ser, y con dar a conocer al Logos y mediante él al Padre. Según 1, 7s, hay una providencia y $\delta v v \alpha \mu \iota \mathrm{s}$ del Logos respecto a todo.

(105) 1,$10 ; 17,9.12 \mathrm{~s} .33 \mathrm{~s} ; 41,14 \mathrm{~s} ; 42,21-23.37$.

(106) $41,14 \mathrm{~s} .27 ; 42,7 \mathrm{~s} .21$. Véase $40,65 \mathrm{~s}$.

(107) 1,$9 ; 12,17 ; 14,32 \mathrm{~s} ; 17,2-4 ; 41,27 ; 42,7 \mathrm{~s} .21-23$. Véase la descripción de CG 44. Este texto termina con el conocimiento por analogía de $\mathrm{Sb} 13,5$.

(108) $12,14-18$. Cf. 14, 32-35.44s, etc.

(109) 8, 3-5. No estaba lejos de nosotros. Cf. 11, 46-49; 17, 2-10 (el universo no está vacío de su

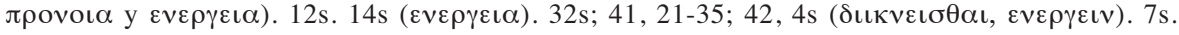
15s. 27s. 34s. 44. 47; 43, 37-39; 45, 8 (1lena todo con su presencia). Viene íntegro, mediante sus potencias, a cada uno y a todos distribuyendo todo con liberalidad (42, 29-31; cf. 17, 5-9). Según 4,24 s, por la presencia y filantropía del Logos, los hombres fueron llamados a existir.

(110) Las otras 6 veces que se usa este verbo se refieren al Logos respecto al todo. Cf. 14, 34s; 45, 12.

(111) $1,8-10$. 
sus partes: él la vivifica y conduce; es su Providencia (112). Pero por otro, también está fuera de ella, porque, como hemos visto, la contiene y no es contenido por ella; la creación es la que participa de él y no él de la creación. Atanasio expresa esto especialmente en el número 17 a propósito de que el Logos no está encerrado en el cuerpo de Cristo, sino que sigue presente en todo el universo con su poder y providencia. Esto es comparado con la presencia del Logos en toda la creación con sus potencias (113), etc., quien, sin embargo, por esencia está fuera de ella (es el que la

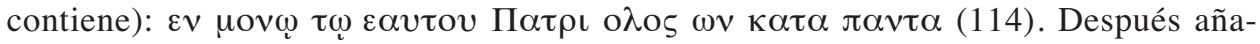
dirá que solo en el Padre reposaba ( $\alpha v \varepsilon \pi \alpha v \varepsilon \tau o)$ (115). Vivía como un hombre, (pero) como Logos engendraba todos los seres a la vida y como Hijo estaba con el Padre (116). En esta última frase integrativa de la comparación anterior, Atanasio indica como tres niveles en el estar del Logos: en su cuerpo, en el universo, en su Padre. Pero respecto al reposo en el Padre, utiliza el nombre de Hijo y contrapone su reposo en el Padre con la actividad del Logos en su cuerpo y en el universo. Según 42,29 s, está entero (o $\lambda \circ \varsigma$ ) en cada cosa y en todas, (pero) por sus potencias. Luego la forma en que está en el cosmos y en el Padre no es la misma. El Logos o Hijo está, pues, en el mundo, pero le es trascendente.

Habiendo visto la creación en general, podemos centrarnos en el hombre. Cuando Atanasio introduce la creación del hombre en 3, 15ss (117) destaca la bondad del Dios sin envidia (118). Este se compadeció del género humano a quien

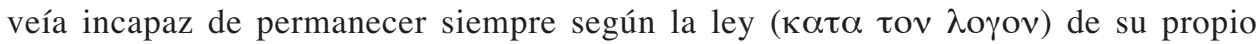
origen; así le regaló algo más. Es decir, hizo a los hombres según su imagen (119) dándoles participación en el poder de su propio Logos (120). Así ellos, teniendo

(112) “Le Logos divin servait de principe d'ordre universel. Par son ubiquité, il garantissait l'harmonie de toutes choses selon le plan providentiel de Dieu" (Kannengiesser, Le Verbe de Dieu, 236).

(113) Afirma G. Florovsky: "There was an absolute dissimilarity between the Logos and the creatures. The Logos is present in the world, but only 'dynamically', that is by His 'powers'. In His own 'substance' He is outside of the world" (The Concept of Creation in Saint Athanasius, en Studia Patristica VI (Oxford 1959), pp. 36-57, p. 46).

(114) 17,10 s. Véase 8,4 s.

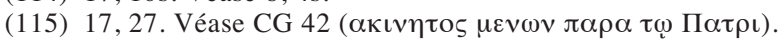

(116) $17,27-30$.

(117) Ya antes, de paso, Atanasio había citado las palabras de Jesús en Mt 19, 4s (el Creador los creó hombre y mujer, etc.) para probar que el Creador es el Padre de Jesucristo. Según 11, 41-44, a propósito de la idolatría y culto a los demonios, etc., dice Atanasio que todos atribuían las causas de su propio origen y existencia a los astros y cuerpos celestes.

(118) Véase también 42,30s; CG 41.

(119) Respecto a la 'semejanza', dice en 11, 19 que Dios los creó según su propia imagen y semejanza (partícipes de su propia imagen, nuestro Señor Jesucristo). Según 4, 30-34, el hombre por naturaleza mortal, si hubiera conservado la semejanza con el que es, por medio de su contemplación, habría permanecido incorruptible. En ningún otro pasaje se habla de la semejanza del hombre con Dios; en cambio, mucho de la semejanza de Cristo con nosotros (unas 11 veces), por el cuerpo. Según el número final, solo cuando el ojo purificado se vuelve casi semejante al objeto deseado, cuando llega a ser luz, puede ver la luz del sol. Así es también para comprender la revelación de Dios (57, 1-18). El cosmos, en expresión de Platón, amenazaba hundirse en la región de la desemejanza $(43,42-44)$.

(120) Según 11,17s, en su bondad los hace participar en su propia imagen, que es nuestro Señor Jesucris-

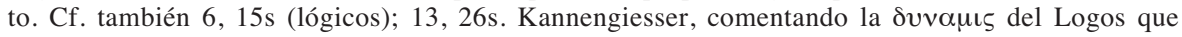
tiene el hombre según CG 2, afirma (Athanase, Sur l'incarnation du Verbe, 76s): "En soi, cette

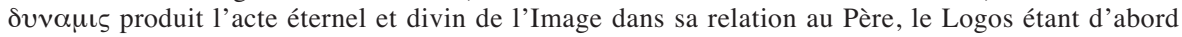

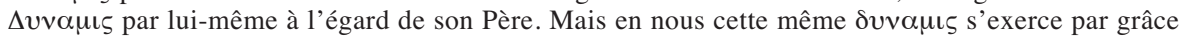


como sombras del Logos y llegados a ser 'lógicos' (121), podrían permanecer en la felicidad (122), viviendo en el paraíso la vida ( $\beta \iota 0 v)$, que realmente es la de los santos (123). Y en 5, 10-12, citando a Sb 2, 23s, agrega nuestro autor que Dios creó al hombre para la incorruptibilidad y como imagen de su propia eternidad, porque, por la gracia del Logos, le había regalado que viviera según Dios (124). Así, por la gracia de la participación del Logos, escaparía de la mortalidad que tenía por naturaleza (125).

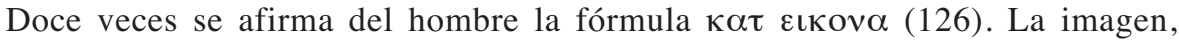
según la que el hombre ha sido creado, es el Logos, el cual es la imagen del Padre. Ya habíamos visto en la primera parte que el Logos es imagen del Padre, imagen $\alpha \pi \alpha \rho \alpha \lambda \lambda \alpha \kappa \tau$ ऽ según CG 41 y 46. En ese sentido, ni los hombres ni los ángeles son la imagen. Los hombres, a diferencia del Logos, solo son según la imagen (127). La imagen en el hombre es comparada a la figura trazada ( $\gamma \rho \alpha \phi \varepsilon \iota \sigma \eta \varsigma)$ sobre la madera, que cuando ha sido borrada podría volver a ser reproducida ( $\alpha \nu \alpha \tau v \pi 0 v \tau \alpha \iota)$

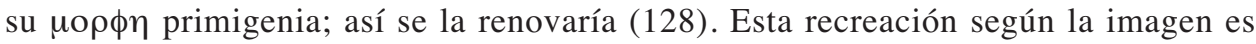
del alma, conforme a 14, 14s (129). Insiste, como acabamos de ver, en que la

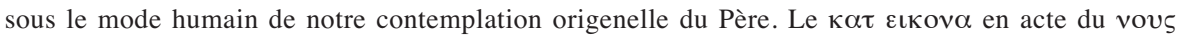

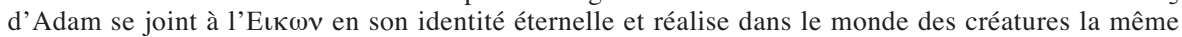
fonction que le Logos au sein de la divinité". Según A. De Nicola (La concezione e la storia del male nel Contra Gentes-De Incarnatione di S. Atanasio, Aug 16 (1976) 85-106, p. 88), "la grazia

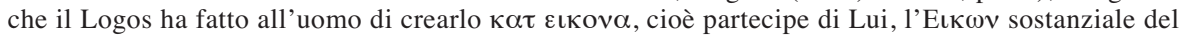
Padre, rendeva l'uomo capace di una conoscenza di Dio tale, che lo rinnovava continuamente riempiendolo di felicità nell'animo e di incorruzione nel corpo".

(121) Según De Nicola (op. cit., n. 46), citando a Roldanus, "in Atanasio i termini logikos e alogos hanno un significato religioso, poichè indicano sempre la relazione dell'uomo verso il Logos, fondata sulla conoscenza che 1'uomo ha di Dio".

(122) Cf. también 3, 33-35; 11, 22s.

(123) Los ángeles. Cf. Kannengiesser, ad 1. c. En el número 2 de CG Atanasio ya había presentado, en un lenguaje más platónico, la vida feliz e inmortal del primer hombre, creado a imagen de Dios, que contempla sin cesar al Logos y en él al Padre. Este lenguaje más platónico se confirma porque en esta obra destaca el alma inmortal y el conocimiento del Logos a través de ella. En cambio, el DI está bajo la lógica del cuerpo, cuerpo que muere por causa de la trasgresión y que hay que volverlo a la vida por medio del cuerpo de Cristo. Por las obras del cuerpo de Cristo conocemos al Logos y mediante él al Padre.

(124) 5, 1-3. Esto además de haberlo creado de la nada. Cf. 4, 35s (relacionado con la incorruptibili$\mathrm{dad})$.

(125) 5, 6-9. Cf. 3, 34s; 4, 14.28-36.

(126) Respecto al tema de la imagen, puede verse la parte primera de Bernard, op. cit. "C'est la sobrieté, la netteté et la fermeté qui nous semblent retenir l'attention sur la doctrine athanasienne de l'image. Peu de thèses: un petit nombre de traits essentiels, mais d'une cohérence, d'une lucidité, d'une constance remarquables" (ib., 11). Véase P. Th Camelot, La théologie de l'image de Dieu, RSPhTh 40 (56) 443-471.

(127) Cf. 13, 31-34. "El hombre recibió, pues, innumerables dones, todos ellos sintetizados en su participación en la Imagen divina. Sin embargo, por ser el hombre una criatura, dicha participación solo era "en sombras"” (E. Contreras, Elementos de antropología teológica cristiana en el "De Incarnatione Verbi" de San Atanasio, Stromata 46 (1990) 361-395, p. 371).

(128) Cf. 14, 1-6. Según CG 34, el alma recupera su pureza de 'según la imagen', desechando toda la suciedad del pecado derramada sobre ella. Recordemos que en esta obra Atanasio no trata de la Encarnación.

(129) Según Kannengieser (Athanase, Sur l'incarnation du Verbe, 77s), "au seul vov..., mais au béné-

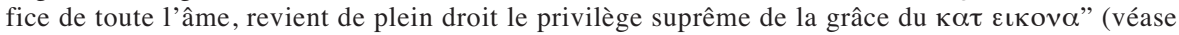
ib., 74-81). Cf. CG 30. Según este mismo autor, el hecho de colocar Atanasio el 'según la imagen' en el vous (cf. p. e. CG 2), le impidió distinguir, con Orígenes, entre imagen y semejanza (Athanasius of Alexandria and the Foundation of Traditional Christology, ThSt 34 (1973) 103- 
creación según la imagen es una gracia (130) más allá del existir, de la que los hombres pueden despojarse (131). Por esta gracia pueden comprender la Imagen, el Logos del Padre, y mediante él alcanzar una idea del Padre (132). Para esto era suficiente la gracia según la imagen (133).

Los hombres, creados de la nada, eran incapaces por sí mismos de conocer a su demiurgo, al Dios increado, incorporal. Pero entonces su existencia sería inútil. ¿Cómo serían 'lógicos', si no conocían al Logos del Padre, en el que habían comenzado a ser? No se diferenciarían de los irracionales. ¿Y para qué los habría creado Dios, si no quería ser reconocido por ellos? Por eso Dios, por bondad y misericor-

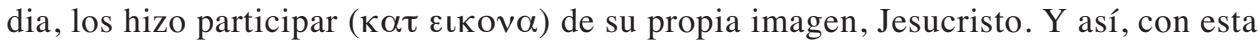
gracia, podían conocer a la Imagen, el Logos del Padre y mediante él tener una idea del Padre (134), como ya vimos. ¿Pero cómo sería el conocimiento del Logos por ellos mismos, que Atanasio insinúa en 12, 4-6? (135). Creo que es el conocimiento que desarrolla en CG como conocimiento por el alma. En el alma está la imagen y en esa imagen se refleja la imagen exacta, que es el Logos.

Según el número 34 del CG (136), cuando el alma se purifica de toda suciedad y añadidura extraña, mostrándose tal como fue creada, puede (137) contemplar en ella al Logos del Padre, a cuya imagen fue creada. Cuando conserva en toda su pureza el ser según la imagen, al brillar esto, con razón contempla como en un espejo al Logos, imagen del Padre y en él descubre ( $\lambda \mathrm{o} \gamma \iota \xi \varepsilon \tau \alpha \iota)$ al Padre, a cuya imagen es el Salvador. Si esto no es suficiente, debido a la turbación que viene de afuera, puede llegar al conocimiento de Dios, dueño y creador, partiendo de las

113, pp. 108-110). Añade Kannengiesser: "Later he had the divine $\varepsilon \iota \kappa \omega v$ itself, in the act of becoming incarnate in a human body, assume all the original functions of the vous of Adam" ( $\mathrm{ib}$., 109). "Thus men become capable of union with God again by the mediation of the incarnate Logos as they had been in the beginning by the mediation of their vous in ecstasy in the Logos" (ib., 110).

(130) Cf. también p. e. 3, 30s; 7, 16-20 (una $\alpha v \alpha \kappa \lambda \eta \sigma \iota \varsigma) ; 11,20.24 \mathrm{~s}$.

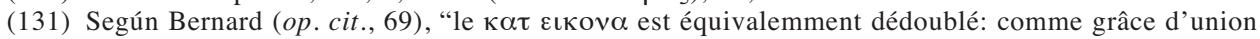
à Dieu il est perdu puis recréé; mais comme ordination de l'âme à Dieu, temoin d'une vocation qui demeure, il subsiste, bien que neutralisé, sous les souillures". Este mismo autor en pág. 51

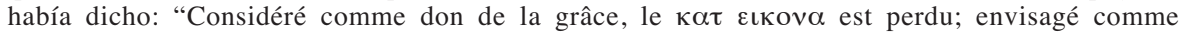
inhérent à l'âme, il n'est qu'obscurci, recouvert d'éléments étrangers”. Según CG 8, el alma (imagen de Dios) $\varepsilon \pi \iota \kappa \rho v \psi \alpha \sigma \alpha$ esa especie de espejo que está en ella.

(132) $11,20-22$. Véase $11,3 \mathrm{~s}$.

(133) $12,1 \mathrm{~s}$. Cf. 13, 28s.

(134) 11, 3-22. Cf. 13, 1-16. Según 11, 22s, los hombres conociendo a su Creador vivirían una vida feliz. En la conclusión de la obra $(57,1-8)$ a propósito del conocimiento del Logos, investigadas las Escrituras por un cristiano virtuoso y purificado, acota Atanasio que el vous puede alcanzarlo y comprender "en la medida en que sea accesible a la naturaleza humana". Cf. 20, 1-3.

(135) Porque el conocimiento por las obras de la creación lo pone Atanasio en esa cita, dada la negligencia de los hombres respecto a este primer conocimiento. Cf. 13, 9s. 28s.

(136) Según el número 2, es capaz de mirar a Dios como en un espejo a través de sí misma (cf. CG 8; véase DI 11,26s), por encima de lo sensible. Según el número 33, el alma, que es inmortal, tiene en sí la idea de la contemplación de Dios, y ella llega a ser su propio camino, tomando no desde fuera sino desde sí misma el conocimiento y la comprensión del Dios Logos. Cf. también CG 30. Respecto al espejo, afirma De Nicola (op. cit., 90): “Ora la metafora dell'anima come specchio comporta l'unione di lei con Dio, poiché lo specchio si riempie della luce emanante dall'oggetto e questo inoltre appare trovarsi dentro lo specchio". De aquí la $\alpha v \varepsilon \pi \alpha \iota \sigma \chi v \nu \tau \omega$ $\pi \alpha \rho \rho \eta \sigma \iota \alpha$ del vous de Adán respecto a Dios (CG 2).

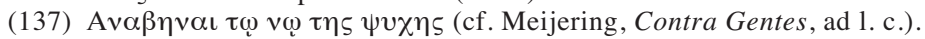


cosas visibles, por la armonía y el orden de la creación (138). En CG 34, exhorta Atanasio simplemente a la purificación del alma para en ella conocer a Dios (139). Recordemos que el CG no entra en la obra de la Encarnación. En el DI, en cambio, del que tratamos en este trabajo y que está centrado en la Encarnación, apenas se alude a este conocimiento por el reflejo en el alma, pero sí se habla muchas veces del conocimiento del Logos por las obras de la creación (140). Y esto varias veces irá en paralelo con el conocimiento de Cristo como Dios, por sus obras (141). Porque al Logos, que es invisible, el hombre debe conocerlo por sus obras (142). El pueblo judío también lo conocía por las divinas Escrituras (143), Escrituras que eran para todos los hombres (144). Porque, por si no miraban al cielo para conocer al Creador, Dios les envió la ley y los profetas para que tuvieran una enseñanza más cercana, por hombres santos (145). En resumen, Dios no había dado a los hombres un conocimiento simple de él, sino que de diversas maneras y a través de muchas cosas lo desplegaba para ellos (146).

\section{EL LOGOS Y EL CUERPO}

El Logos, entonces, no solo podría ser conocido en el alma creada a su imagen y por las obras de la creación, sino que, dado nuestro pecado, también por las obras del Logos encarnado por nuestra salvación. Pero antes de entrar en las causas de la Encarnación, veamos primero como esta es dicha y la relación del Logos a su cuerpo. La Encarnación es expresada de múltiples formas (147). La encarnación

(138) Atanasio, según L. A. Sánchez Navarro (Atanasio, Contra los paganos, Madrid 1992, ad 1. c.), ha dejado para el final el argumento más claro para mostrar la existencia de un solo Dios: el orden del cosmos. De esto tratará extensamente en los números siguientes del CG.

(139) Así como se apartaron, pueden volverse de nuevo hacia Dios.

(140) P. e.: $2,15-18 ; 12,5$ s.9s.13-18; 14, 31-38; 41, 16s.29.34s. Pero en 57, 1-18 habla de la purificación del alma para el conocimiento del Logos por casi semejanza.

(141) P. е.: $14,42-47 ; 17,14 s ; 18,17-21 ; 19,1-7 ; 41,28-35 ; 42,34-40 ; 43,21-37 ; 45,3-36 ; 53,28-33$; 54, 1-13. Véase $17,4-6$.

(142) Cf. p. e. $16,25-28 ; 18,17-21 ; 32,2-10 ; 42,34-36 ; 43,28-30 ; 54,1-13$. Véase CG, p. e. 35

(143) CG 45. Cf. p. e. CG 1; 46; DI 12, 8-29; 56, 5-7; 57, 1s.

(144) Cf. DI 12, 24-29. Meijering, en Contra Gentes, 114s, enumera los 4 caminos que presenta Atanasio para conocer a Dios: "the first one is in the fact that man was created in God's image (this was discussed so far in the Contra Gentes), the second one is through the harmony of the universe (this will be discussed in CG 35-45a), the third one is through the law and the prophets of the Old Testament (this will be discussed in CG 45b-46), the fourth one is through the incarnation of the Word (this will be discussed in the bulk of the De Incarnatione Verbi)".

(145) Cf. 12, 7-29. Por la ley podían vivir según la virtud. Véase CG 45s.

(146) $11,47-49$

(147) Se puede ver la lista de las menciones de la Encarnación que trae Kannengiesser (Athanase, Sur l'incarnation du Verbe, 93-139). Según ella, Atanasio utilizaría 51 verbos en unas 187 ocasiones, y 17 substantivos en unas 51 ocasiones.

Este autor connota la repectiva doctrina del DI como "archaïque et assez peu formalisée" (p. 93). Destaca la elevada proporción de vocabulario exclusivo de De Incarnatione en relación a las otras obras de Atanasio (p. 138). 
( $\varepsilon v \alpha v \theta \rho \omega \pi \eta \sigma \iota \varsigma)$ es una divina $\varepsilon \pi \iota \phi \alpha v \varepsilon \iota \alpha$ (148) del Logos (149), del Salvador (150); epifanía corporal (151), en un hombre (152). Porque no se trata de mostrarse y causar estupor, sino que sea útil para nosotros (153). El Logos, siendo incorporal por naturaleza, por nosotros se ha hecho visible en un cuerpo (154). Notemos que los numerosos vocablos de 'manifestación' están bastante conectados con el cuerpo. En cambio o $\alpha \rho \xi$ casi no aparece en esta obra (155), ni nunca es directamente citado Jn 1, 14.

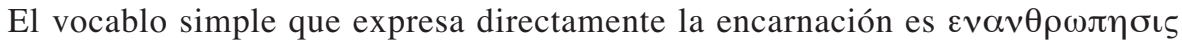
(156). Con varias expresiones, ya aparecidas o por aparecer, Atanasio indica que el Logos se hace hombre (157), pero más veces utiliza para esto el vocablo $\sigma \omega \mu \alpha$. Así el Logos $\lambda \alpha \mu \beta \alpha v \varepsilon \iota \varepsilon \alpha v \tau \omega \sigma \omega \mu \alpha$ (158), semejante al nuestro y que puede morir. Lo

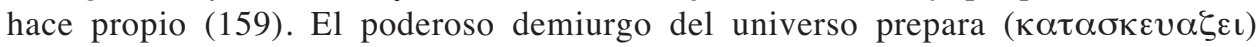
para sí (160) un templo (el cuerpo) en la Virgen y en él inhabita (161). Se revistió de un cuerpo (162). También utiliza, en referencia a la Encarnación, algunas expre-

(148) El vocablo $\varepsilon \pi \iota \phi \alpha v \varepsilon \iota \alpha$ es usado 12 veces (excluido el título) para referirse directamente a la Encarnación y una para referirse a la segunda venida en gloria (ya no en $\varepsilon v \tau \varepsilon \lambda \varepsilon \iota \alpha$ y $\tau \alpha \pi \varepsilon \iota v o \tau \eta \varsigma) ~ d e$

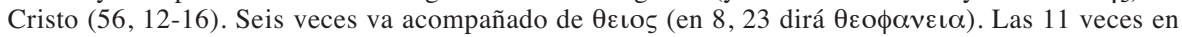
que es utilizado el verbo $\varepsilon \pi \iota \phi \alpha \iota v \omega$ son en referencia a la Encarnación, y prácticamente las 6 veces



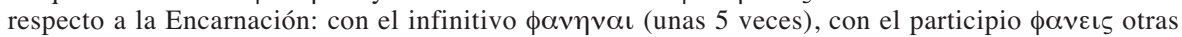

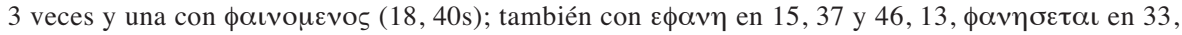

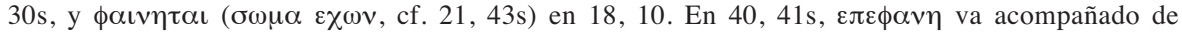
$\varepsilon \pi \varepsilon \lambda \alpha \mu \psi \varepsilon$. Véase $38,7.10 \mathrm{~s}$. Habiendo el pensamiento de los hombres caído a lo sensible, el Logos se abajó ( $v \pi \varepsilon \beta \alpha \lambda \varepsilon v \varepsilon \alpha v \tau o v)$ a manifestarse ( $\phi \alpha v \eta v \alpha \iota)$ a través de un cuerpo $(16,1-3)$.

(149) 1, 12-14. Véase el título de la obra, que no aparece en la recensión breve. Véase 47, 11.24; 54, $13 \mathrm{~s} ; 55,17 \mathrm{~s}$, etc.

(150) Cf. p. e. 4,$5 ; 29,16$.

(151) 20,$1 ; 29,16 ; 37,42 \mathrm{~s}$. Cf. 1, 29-32.32-36;4, 12s; 16, 2s. 20s; 18, 40s; 29, 16.17s; 38, 12s; 40, $41 \mathrm{~s} ; 41,7 \mathrm{~s} .29 \mathrm{~s} ; 42,24 \mathrm{~s} .38-40 ; 54,13 \mathrm{~s} ; 55,34$. Véase el título de la obra.

(152) 42,12 . Véase 15,$37 ; 33,30 \mathrm{~s} ; 37,28 \mathrm{~s} ; 42,38 \mathrm{~s} ; 43,47 \mathrm{~s}$, etc.

(153) Cf. 43, 6-12.

(154) 38,12 s. Cf. 1, 32-36; 38, 10s ( $\varepsilon \mu \phi \alpha \nu \eta \varsigma)$.

(155) Salvo en dos citas de $\mathrm{Hb}(2,14 \mathrm{~s}$ y 10,20$)$ y, en la discusión con los judíos, aludiendo a la generación de Cristo según la carne (4 veces). La $7^{\text {a }}$ vez es respecto al matrimonio, según Mt 19, 4 s. No usa ningún compuesto de $\sigma \alpha \rho \xi$.

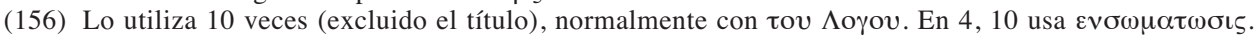
"Der lateinische Titel "De incarnatione" ist -genau betrachtet- nicht ganz korrekt; denn Athanasius spricht darin nie von einer "Fleischwerdung", sondern von der "Menschwerdung" ( $\varepsilon v \alpha v \theta \rho \omega \pi \eta \sigma \iota \varsigma)$ des Logos und beschreibt den Vorgang der "Inkarnation" als Verleiblichung ( $\varepsilon v \sigma \omega \mu \alpha \tau \omega \sigma \iota \varsigma)$,


Zur Logos-Christologie des Athanasius von Alexandrien in Contra Gentes und De Incarnatione, en Studia Patristica, XXI (Oxford 1987), 402-419, p. 404).

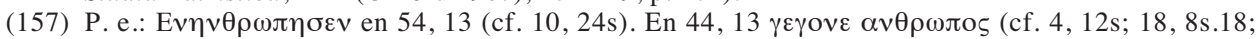

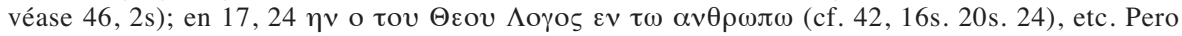
en 41,25 s dice $\varepsilon v \sigma \omega \mu \alpha \tau \iota ~ \alpha v \tau o v ~ \gamma \varepsilon v \varepsilon \sigma \theta \alpha \iota$ (cf. 4, 12s; 8, 21; 44, 32s). Y en 17, 31, $\varepsilon v \sigma \omega \mu \alpha \tau \iota$

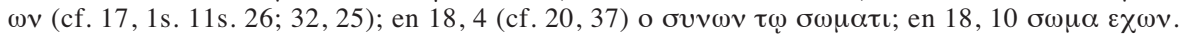

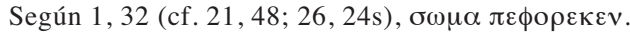

(158) 8, 20s. 12 veces usa esta expresión. Cf. 45, 1s. Véase $\sigma \omega \mu \alpha \tau o \varsigma \alpha \psi \alpha \sigma \theta \alpha \iota$ en 44, 4.

(159) 31, 29s. Cf. 8, 28s (como instrumento). 39. Así unas 9 veces su cuerpo es llamado ıoıov.

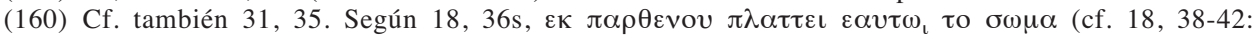

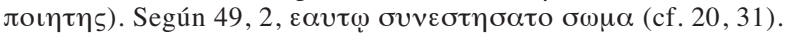

(161) 8, 27-30. De inhabitación en su cuerpo habla 3 veces más (véase 9, 27), y este es llamado vaos otras 5 veces.

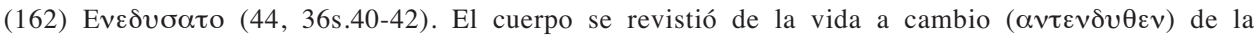
corrupción, para expulsarla, entrelazándose ( $v \mu \pi \lambda \alpha \kappa \eta v \alpha \iota, \sigma v \mu \pi \lambda \alpha \kappa \varepsilon v \tau o \varsigma)$ con ella (44, 29-41; cf. 44, 59). Se revistió del incorporal Logos de Dios $(44,57)$. 
siones que indican desplazamiento o presencia. Así el Logos descendió (163) y vino (164) a vivir entre nosotros (165). Es el Emmanuel, el Dios con nosotros (166).

El encarnado es, pues, el Logos de Dios en un cuerpo (167). Detengámonos ahora en el tema de su cuerpo, del que habla unas 147 veces usando $\sigma \omega \mu \alpha(168)$. Se trata de un cuerpo humano (169), individual (170), semejante al nuestro (171, mortal (172); pero de un cuerpo puro, nacido de una virgen sin mancha (173). En cuanto cuerpo, era dado a luz, nutrido con alimentos apropiados, comía, bebía y padecía, mostrándose así como cuerpo verdadero y no imaginario (174).

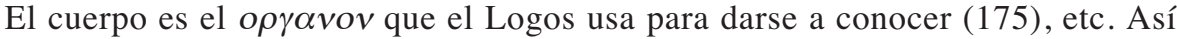
como el Logos no participa ( $\mu \varepsilon \tau \alpha \lambda \alpha \mu \beta \alpha v \varepsilon \iota)$ de nada de la creación, en la que está, así tampoco participa ( $\mu \varepsilon \tau \varepsilon \iota \chi \varepsilon v)$ de nada del cuerpo, sino que lo santifica (176). El Logos no padece en el nacimiento de la Virgen ni sufre daño en su 'Pasión' (177). El Logos mueve e ilumina el universo y su cuerpo (178). Así como la muerte se


expulsar la corrupción (179). El Logos toma un cuerpo para morir y así borrar la

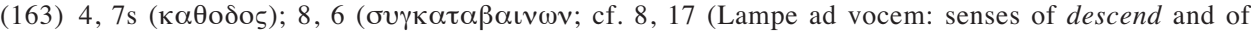

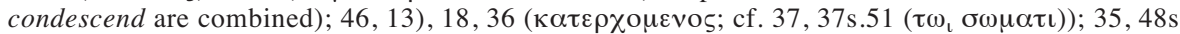

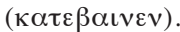

(164) $\Omega \varsigma \alpha v \theta \rho \omega \pi \circ \varsigma \varepsilon \pi \iota \delta \eta \mu \varepsilon \iota ~(14,42$; cf. las otras 6 veces que usa el verbo $\varepsilon \pi \iota \delta \eta \mu \varepsilon \iota v$ y las 4 que utiliza $\varepsilon \pi \iota \delta \eta \mu \iota \alpha))$. Ev $\alpha v \theta \rho \omega \pi \omega_{\iota} \alpha v \tau$ ov $\varepsilon \pi \iota \beta \eta \beta \varepsilon \kappa \varepsilon v \alpha \iota ~(41,24 \mathrm{~s})$. Hay una $\varepsilon \pi \iota \beta \alpha \sigma \iota \varsigma$ del Logos a su cuerpo $(20,33.43 \mathrm{~s} ;$ cf. 31,$32 ; 43,26)$. De las 14 veces que usa $\pi \alpha \rho o v \sigma \iota \alpha, 7$ están referidas más directamente a la Encarnación como venida o como presencia del Logos entre nosotros (cf. también $40,9)$. El Logos de Dios, imagen del Padre, vino ( $\pi \alpha \rho \varepsilon \gamma \varepsilon v \varepsilon \tau o)$ por sí mismo a recrear al hombre según imagen $(13,34-36$; cf. $13,30 \mathrm{~s} ; 14,6-8)$. Véase $8,2.5 \mathrm{~s} ; 9,32 ; 13,20 ; 16,17 \mathrm{~s} ; 38,41 \mathrm{~s}$ ( $\varepsilon v$ $\sigma \omega \mu \alpha \tau \iota) ; 38,42-44 ; 39,3 \mathrm{~s} ; 40,3 \mathrm{~s} ; 44,12-14$. Cf. 46, 2s. Entre los usos del verbo $\varepsilon \rho \chi \varepsilon \sigma \theta \alpha \iota$ para expresar su venida, tenemos: $9,26 \mathrm{~s} ; 33,31 \mathrm{~s} ; 40,8.11$ s. 20-22. 25. 36. 50. 64s; 55, 17s. Cristo es o $\varepsilon \kappa \pi \alpha \rho \theta \varepsilon v$ ov $\pi \rho \circ \varepsilon \lambda \theta \omega \nu(27,38 \mathrm{~s} ;$ cf. $18,39 \mathrm{~s}$; véase $37,39 \mathrm{~s})$. Véase $\phi \theta \alpha \sigma \alpha \iota$ en $4,9$.

(165) Se estableció $(\varepsilon \kappa \alpha \theta \iota \sigma \varepsilon)$ en la humanidad $(43,47 \mathrm{~s}$; cf. 16, 21). Vive ( $\alpha \nu \alpha \sigma \tau \rho \varepsilon \phi \varepsilon \tau \alpha \iota)$ como hombre entre los hombres $(15,14)$. Véase 19, 22s ( $\varepsilon v \sigma \omega \mu \alpha \tau \iota ~ \delta \iota \alpha \gamma \omega \gamma \eta ; \pi \varepsilon \rho \iota \pi \circ \lambda \varepsilon \sigma \iota \varsigma) ; 17,28$ ( $\omega \varsigma \alpha v \theta \rho \omega \pi \circ \varsigma \varepsilon \pi 0 \lambda \iota \tau \varepsilon v \varepsilon \tau o)$. Está $\sigma \omega \mu \alpha \tau \iota \kappa \omega \varsigma \pi \alpha \rho \omega v(18,11 ;$ cf. 40, 9. 14).

(166) 33,17 , citando Mt 1,23 (Is 11,14 ).

(167) Cf. 14, 46s.

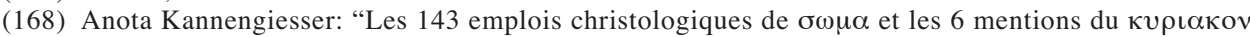
$\sigma \omega \mu \alpha$ en DI mériteraient de faire l'objet d'une étude particulière, en rapport avec la terminologie ultérieure d'Athanase" (Athanase, Sur l'incarnation du Verbe, p. 139 n. 1).

(169) 1,$35 ; 4,12 \mathrm{~s} ; 17,11 ; 20,30 ; 41,30 ; 42,9 ; 43,25 \mathrm{~s} ; 44,13 \mathrm{~s} ; 45,1 \mathrm{~s}$. Cf. 42, 44s; 44, 21s.

(170) Insiste en esto en $9,19 \mathrm{~s} .27 \mathrm{~s} ; 42,9$, etc.

(171) Cf. 8, 20-24. 30. 35s; 9, 10s. 15. 27s; 10, 31s; 14, 42s; 20, 31s. Véase 37, 16 (semejante por naturaleza); 43, 29s. 31; 44, 18. Su cuerpo tiene la esencia común a todos $(20,29 \mathrm{~s})$. Es un prodigio el que se produzca solo de una virgen (cf. 20,30 s; véase $18,36-42 ; 33,13-16$ ). 13 veces se refiere al nacimiento de una virgen. Véase $34,25 \mathrm{~s}$.

(172) 13,$38 ; 17,40 ; 20,30 \mathrm{~s} ; 44,37$ s.55s. Cf. 20, 41s; 23, 17; 31, 33s.37; 44, 44s, etc.

(173) 8, 24-28 (sin relación sexual). El Logos nada padeció, al dar a luz la Virgen $(17,30)$.

(174) Cf. 18, 1-3.6-10. Pero del Logos se dicen estas cosas, porque el cuerpo era suyo. Según lo propio del cuerpo, tuvo hambre, pero no pereció de hambre (cf. 21,47s). Fueron traspasados sus manos y sus pies en la cruz (cf. 35, 12s.17s; 37, 1-3; véase 38,6.11).

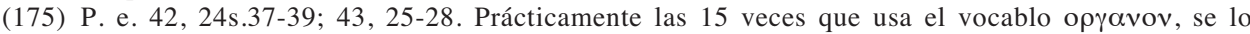
aplica al cuerpo, salvo en 43,2 .

(176) 43, 37-41. No es manchado por el cuerpo sino que más bien lo santifica $(17,31 \mathrm{~s} ; \mathrm{cf} .17,34-37)$; lo vivifica y purifica $(17,38-42)$. Véase cita de Hb 2, 14 en 10, 33s. El cuerpo participa del Logos $(9,4-6)$. En CG 47 el Logos había sido llamado $\alpha v \tau o \alpha \gamma \iota \alpha \sigma \mu \sigma_{5}$ respecto a las creaturas.

(177) Cf. 17, 30; 54, 17-20

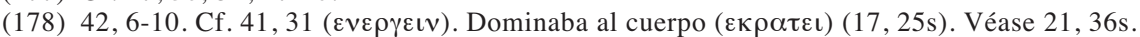

(179) 44, 24-32. Ni la muerte ni la vida eran exteriores al cuerpo. Véase 44, 36-38. 
muerte que se encuentra en el cuerpo (180). Murió como mortal y volvió a vivir por la vida que estaba en él (181). Inhabitando el Logos en los hombres mediante un cuerpo individual (182), se extendió a todo (183). Este es el principal motivo de la importancia del cuerpo. Así, al menos unas 85 veces, $\sigma \omega \mu \alpha$ va conectado con su muerte y resurrección. Otro motivo es para ser conocido mediante las obras de su cuerpo (184). Hecho hombre, no era visto en su cuerpo, sino conocido por sus obras (185). Según 32, 32-36, en los últimos tiempos el Logos tomó cuerpo para salvación de todos; enseñó sobre su Padre, destruyó la muerte y regaló a todos la incorruptibilidad mediante la promesa de la resurrección, resucitando su propio cuerpo como primicia de esta. A estos dos motivos me referiré más adelante.

En conclusión, que el Logos tomó un cuerpo es lo mismo que decir que se hizo hombre. A esto se añade que Atanasio no menciona el alma de Cristo (186). En CG había demostrado la existencia del alma humana razonable, y probado su inmortalidad (187). Ella es camino para el conocimiento de Dios. Y en DI se refiere 12 veces a la $\psi v \chi \eta$ humana, pero nunca a la del Salvador. Según 17, 1-30, contrariamente al alma humana que no puede mover nada a distancia (188), el Logos no estaba encerrado en el cuerpo ni atado a él, sino que estaba presente en el universo con su $\varepsilon v \varepsilon \rho \gamma \varepsilon \iota \alpha$ y providencia, ordenándolo todo con sus $\delta v v \alpha \mu \varepsilon \sigma \iota$ (189), vivificando, y estando a la vez íntegramente en su Padre (190). Él contiene todo, pero no es contenido por nadie; estando en todo, por naturaleza es exterior al universo. Podría llamar la atención esta comparación, aunque negativa, del Logos y del alma respecto al cuerpo (191). Por otro lado, todo el universo forma un gran cuerpo en el que, como vimos en la parte anterior sobre la creación, está el Logos moviendo, iluminando y vivificando. De ahí concluye Atanasio que no es insensato que el Logos utilice para manifestarse una parte de ese todo, es decir, el cuerpo

(180) $44,42 \mathrm{~s}$.

(181) Cf. 44, 38s. Gracias a su propio cuerpo nos ha llevado hacia arriba, nos ha abierto el camino a los cielos $(25,43-45)$.

(182) $9,19 \mathrm{~s}$.

(183) 44, 21s. Comenta Kannengiesser (ad 1. c.): "Devenu homme par son incarnation, le Logos réalise l'unité de tous les hommes selon le mode de communion propre à la condition corporelle, qui rend les êtres humains participants de la même nature physique. Demeurant le Logos créateur de l'universelle création jusqu'en cette kénose de son incarnation, il réalise d'une manière nouvelle sa présence dans le cosmos. La notion stö̈cienne de 'l'extension' du Logos à tous les êtres se trouve bien liée désormais à la notion athanasienne de son incarnation".

(184) Los hombres al final van a ser juzgados por lo que hicieron mediante el cuerpo (56, 19s. 29-32).

(185) Cf. 18, 18s. Cf. 54, 1-5.

(186) Cf. p. e. P. Galtier, Saint Athanase et l'âme humaine du Christ, Greg 36(1955)553-589, pp. 563589. "De même, nous paraît-il,...que saint Athanase, comme d'ailleurs saint Cyrille plus tard, s'est fort peu occupé de la psychologie humaine du Christ. En lui, ce que l'un et l'autre se sont attachés à faire ressortir, c'est constamment le Fils de Dieu lui-même" (ib., 570). Según este mismo autor, "après avoir affirmé que ce qui fait l'homme, c'est son âme, parler d'un home qui vit une vie et meurt d'une mort d'homme; qui ignore et progresse à la manière des hommes, et en parler ainsi à des hommes habitués à considérer l'homme comme composé d'un corps et d'une âme, c'est bien faire entendre qu'on lui reconnaît la même constitution" (ib., 589).

(187) Puede verse Meijering, Contra Gentes, 98ss.

(188) Comparar con CG 33.

(189) Véase también $18,4 \mathrm{~s}$.

(190) Véase también 8, 3-7.

(191) Véase también 42, 1-10. 
de Cristo, al que igualmente mueve e ilumina y vivifica (192). A. Grillmeier dirá hablando de Atanasio (193): "Si la relación Logos-mundo se transfiere primero al alma y al cuerpo (como trasunto de la primera relación) (194) y después a Cristo, el Logos tiene que ser el principio motor y vivificante del cuerpo de Cristo, debe

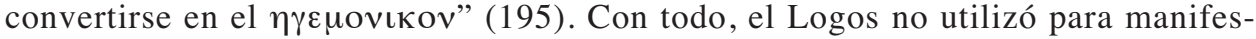
tarse un instrumento como el sol, etc., sino un cuerpo humano, porque vino a curar y enseñar a los hombres, los únicos desviados (196). Esto último, entre otras cosas, muestra la diferencia entre la actuación cósmica del Logos y la encarnación. El santísimo (197) Logos es comparado al sol, e igual que este, no se mancha por estar en el cuerpo, sino que lo purifica (198). El Logos no podía salvar con un solo acto de voluntad, con una simple orden, sin tocar el cuerpo, como cuando creó de la nada. Porque no era la nada la que necesitaba de salvación, sino el hombre. El Salvador tenía que curar al ya existente. El hombre necesitaba de su divinidad por medio de un instrumento semejante (199). Como se dijo poco antes, la corrupción no era exterior al cuerpo, por eso la vida tenía que entrelazarse con él para expulsarla.

¿Desplaza el Logos el alma de Jesús? La muerte puede ser expresada como un deponer $(\alpha \pi \sigma \theta \varepsilon \sigma \theta \alpha \iota)$ el cuerpo (200) de parte del Logos, según la costumbre humana (201). Y en 22, 28 es expresada la hipotética muerte por enfermedad,

(192) Cf. 17, 11-13; 41, 18-35; 42, 6-47. Véase 43, 34-37. Kannengiesser, comentando 42, 16s, dice: "L'analogie entre la présence universelle du Logos créateur et celle du Logos incarné dans son corps personnel frise l'équivoque depuis le début de ce paragraphe. Elle paraît inapte à suggérer aux non-chrétiens la nouveauté essentielle du mystère de l'Incarnation".

(193) Jesus der Christus im Glauben der Kirche, I, $2^{\mathrm{a}}$ ed. Herder 1982, p. 465: "Wenn das Logos-WeltVerhältnis zunächst auf Seele und Leib (als Abbild des ersten Verhältnisses), dann auf Christus übertragen wird, so muss der Logos das bewegende und belebende Prinzip des Leibes Christi

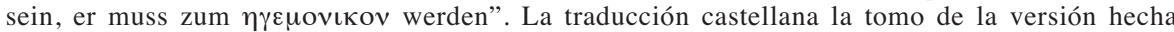
sobre la $3^{\mathrm{a}}$ ed. alemana de este libro: Cristo en la tradición cristiana. Desde el tiempo apostólico hasta el concilio de Calcedonia (451) (Verdad e Imagen, 143) Salamanca, 1997, p. 508.

(194) Este mismo autor había dicho en la página anterior: "Die menschliche, vernünftige Seele aber ist das vollkommenste Abbild des Logos innerhalb der irdisch-leiblichen Schöpfung. Sie erfüllt dem Leibe gegenüber jene Aufgabe, welche der Logos im Kosmos hat. Sie ist ein Logos im kleinen und darum auch ein Weg zu ihm und zum Vater".

(195) "Der entscheidende Zug der stoisch-alexandrinischen Logoslehre drängt sich sofort in den Vordergrund: das Bestreben, den Logos zur allbelebenden und allbewegenden Kraft zu machen" (ib., 463). El Logos, para Atanasio, es como el alma del cuerpo del universo. Y si el Logos es capaz de animar todo el cosmos, cuanto más una parte de él, donde mora en toda su plenitud, como en su templo $(i b ., 464 \mathrm{~s})$.

(196) Cf. 43, 1-21; 44, 11-22. Véase 8, 21-24.

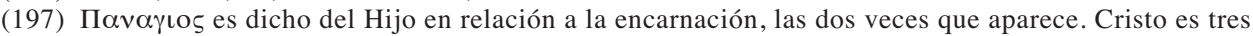
veces designado como 'santo de los santos'. Véase también 32, 26.

(198) $17,34-42$. Véase $29,10-20 ; 55,15-20$.

(199) Cf. 44, 1-22. Véase 44, 23-60.

(200) $21,20 \mathrm{~s} ; 22,8.15 \mathrm{~s}$. Recordemos la contraria imagen de 'revestirse'. Kannengiesser comenta así 22, 8: "La séparation du Logos d'avec son corps est le signe distinctif de la mort du Christ selon cette expresion d'Athanase et l'argumentation du paragraphe précédent". Cf. Camelot, ad 22, 28.

(201) 21, 31s. En CG 33 había dicho que la muerte del cuerpo es por la retirada del alma, que le da el movimiento. 
como una separación del $\operatorname{Logos}(\delta \iota \alpha \lambda v \theta \varepsilon \iota \varsigma \alpha \pi 0)$ (202) respecto al cuerpo (203). Gregorio de Nisa, en su Gran Catequesis, dirá, años después, que la muerte es la separación del alma y del cuerpo, permaneciendo el Logos unido a ambos; y la resurrección será volver a juntarlos (204). Para terminar, creo que la gran razón para que no aparezca el alma de Jesús, es que Atanasio explica la redención mediante el solo cuerpo del Logos (205). Según Grillmeier, Atanasio no niega en sus escritos el alma de Cristo, pero atribuiría directamente al Logos la vivificación del cuerpo de este (206).

Hecha esta primera aproximación a la Encarnación, es conveniente ver ahora los nombres y títulos del encarnado (207), de los que no haya tratado antes. El primero es 'Cristo', que aparece 104 veces (208). Diez veces conforma Jesús Cristo, y 1 Cristo Jesús (209). Ocho veces va acompañado de 'nuestro Señor' (210) y otras

(202) Cf. 21, 27. Las otras 4 veces que se usa $\delta \iota \alpha \lambda v o u \alpha \iota$ expresa la descomposición. Igualmente la única vez que aparece $\delta \iota \alpha \lambda v \sigma \iota s$.

(203) J. Lebon afirmó que la opinión, corriente en la época, de que en la muerte de Jesús se separó el Logos del cuerpo, no excluía el alma de Jesús, tema todavía poco reflexionado (Une ancienne opinion sur la condition du corps du Christ dans la mort, RHE 23 (1927) 5-43; 209-241, pp. 235241).

(204) Cf. Zañartu, op. cit. 587.

(205) Expresa G. C. Stead (Athanasius' De Incarnatione: An Edition Reviewed, JTS 31(1980)378-390, p. 390) respecto al Logos: "he assumed a body like ours in order that the human body as such could be revived and purified (); and it is here that one feels it most disturbing that Athanasius did not apply this principle to the soul". Véase id., The Scriptures and the Soul of Christ in Athanasius, VC 36 (1982) 233-250.

(206) Op. cit., 460-479. "Man kann wohl ziemlich eindeutig und sicher aufzeigen, dass die Seele Christi bei Athanasius keine 'theologisch-soteriologische Grösse' ist. Sie ist für ihn kein Faktor in der Ausdeutung des Heilswirkens, aber auch nicht einmal des inneren menschlichen Lebens Christi" (ib., 460). "Mit aller Ehrlichkeit werden wir auch die Elemente aufzeigen, welche dahin gedeutet werden und dahin führen können, dass die Seele Christi auch keine physische Grösse ist" (ib., 461). "Wo das Urbild mit seiner Kraft selbst erscheint, hat das Abbild mit seiner abbildlichen und abgeleiteten Kraft zum mindesten seine Aufgabe, wenn nicht überhaupt seinen Platz abzutreten" (ib., 464). "Ohne Zweifel ist der Logos nicht bloss der personhafte Träger des leiblichen lebens in Christus, sondern auch die reale, physische Quelle aller Lebensakte" (ib., 465). Y prosigue Grillmeier: "Es ist aber ziemlich wahrscheinlich, dass der Logos als Logos von Athanasius als geistiges Vollzugsprinzip des eigentlichen Erlösungsaktes angesehen wird" (ib., 467). Y pese a que los arrianos atacaban la divinidad del Logos señalando debilidades en la sicología humana de Cristo, observa nuestro autor: "Nicht ein einziges Mal im Laufe seiner langen Kritik tadelt er an seinen Gegnern, dass sie die menschliche Seele des Herrn vergessen hätten" (ib., 462). Más bien tiende a atenuar el carácter anímico de ciertos procesos internos del Señor, cuyo sujeto físico pasa a ser la carne (cf. ib., 467-469). "Wie der Lebende Christus des Athanasius, so zeigt auch der sterbende seine Seele nicht. Der Tod des Herrn wird aus dem Schema 'Logos-Sarx' erklärt und hingestellt als eine Trennung des 'Logos' vom Leibe. Dieser ist es auch, der hinabsteigt in die Unterwelt" (ib., 469). "Die Betonung der Einheit bleibt freilich die Grundrichtung seiner Christologie" (ib., 478). Cf. M. Richard, Saint Athanase et la psychologie du Christ selon les ariens, MSR 4 (1947) 5-54.

(207) Dice Kannengieser (Athanase, Sur l'incarnation du Verbe, 86s): "LOGOS.- L'emploi de ce titre est massif en DI, soit pour désigner le Fils préexistant, soit por nommer Jesús. On en compte 142 mentions, contre par exemple 82 de CRISTOS et 64 de SÔTER, les plus fréquentes en ordre décroissant". Etc.

(208) El verbo $\chi \rho \iota \omega$ es usado 3 veces respecto al Santo de los santos.

(209) 'Jesús' solo en 10, 21 es usado sin combinarse con 'Cristo'.

(210) Cristo Señor en 15, 23. Cf. 45, 25s. 


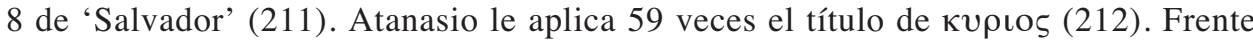
al sabor a veces creacional de $\kappa \cup \rho \iota \varsigma_{5}$, las 68 veces que lo designa como $\sigma \omega \tau \eta \rho$ (213) son exclusivamente en contextos de encarnación y salvación (214). Estos son los grandes nombres repetidos muchas veces. Pero tiene también una serie de otras designaciones dispersas (215). Así, entre otras cosas, es el $\delta \varepsilon \sigma \pi \sigma \tau \eta \varsigma$ de todo lo que anda sobre las aguas (216). Es el esperado (217) de la raíz de Jessé (218), el profeta (219). El Hijo del hombre (220). Es el ı $\alpha \tau \rho \circ \varsigma$ que viene a curar (221). Es el $\alpha \rho \chi \eta \gamma o \varsigma$ de la salvación (222). Es la $\alpha$

\section{CAUSAS DE LA ENCARNACIÓN Y EL MODO SALVÍFICO DE SU OPERAR}

\section{a) La situación del hombre y la reacción de la bondad de Dios}

Para tratar de la Encarnación, Atanasio se ve obligado a hablar del comienzo de los hombres, porque nuestra culpa fue el motivo de su descenso, nuestra trasgresión provocó la filantropía del Logos (224). Como ya hemos visto al tratar de la creación del hombre, Dios hizo al hombre según su imagen y este podía permanecer en la felicidad viviendo en el Paraíso. Por la gracia de la participación del Logos escaparía de su mortalidad natural. Dios quería que el hombre permaneciera en la incorruptibilidad (225). Si este hubiera conservado la semejanza mediante la contemplación de Dios, habría desactivado la corrupción natural y permanecido incorruptible (226). Gracias al Logos que estaría ( $\sigma v v \omega v)$ con él, la corrupción natural no se habría acercado (227). Pero no fue así (228). La trasgresión del mandamiento

(211) Común salvador de todos $(30,4 \mathrm{~s} ; 37,27 ; 52,3)$.

(212) Es decir todas las veces que se usa, salvo 33, 25 (Dios del A. T.) y 46, 31s (un ídolo) . A él está

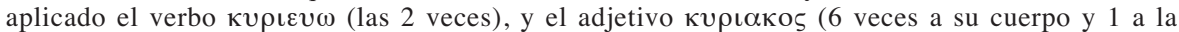
cruz). Kupıos está en referencia al 'creador' unas 7 veces, y otras 5 va como señor de todo o de la gloria.

(213) Este vocablo solo se aplica a él. Cristo es el sujeto del verbo $\sigma \omega \zeta \omega$ y compuestos unas 7 veces.

(214) Con todo, está también en referencia a la creación en 20, 4 y 49, 5-11.

(215) La alternancia de designaciones de Cristo, además de una mayor consonancia con lo que está afirmando, en parte se podría simplemente deber a no repetir. Véase p. e. el núm. 46.

(216) Cf. 9,$31 ; 18,45-47 ; 46,12 . \Delta \varepsilon \sigma \pi 0 \tau \eta 5$, las otras 4 veces en que es usado, está también aplicado a Cristo.

(217) 40, 50. Esperanza de los gentiles (cf. 35, 21-23; 36, 12.25s; 37, 46s; 40, 21s.31s).

(218) Cf. 35, 21-23 (cf. Is 11, 10); 40, 32s. Cf. 33, 21s ( $\alpha \sigma \tau \rho o v ; \alpha v \theta \rho \omega \pi \circ \varsigma) .26 \mathrm{~s}(\alpha v \theta \rho \omega \pi \mathrm{s}) .30 \mathrm{~s}$ $(\alpha v \theta \rho \omega \pi \mathrm{s})$. Véase 34,8 (Is 53, 3).

(219) $38,8-11$.

(220) 56, 23s (cf. Mt 26, 64).

(221) 44, 12s. 8 veces se le aplica el verbo $\theta \varepsilon \rho \alpha \pi \varepsilon v \omega$. Véase 34,$15 ; 40,44$.

(222) Citando a $\mathrm{Hb} 2,10(\alpha \gamma \alpha \gamma o v \tau \alpha)$ en 10, 27.

(223) 40, 11. De $\alpha v \tau o \zeta \omega \eta$ ya se había tratado antes. Igualmente de $\zeta \omega \eta, \alpha \lambda \eta \theta \varepsilon \iota \alpha, \beta \alpha \sigma \iota \lambda \varepsilon v \varsigma, \eta \gamma \varepsilon \mu \omega \nu$, $\chi о \rho \eta \gamma о \mathrm{~s}, \alpha \sigma \omega \mu \alpha \tau \mathrm{\tau}_{\mathrm{s}}$, etc.

(224) Cf. 4, 1-13.

(225) 4, 14. Cf. 5, $11(\mathrm{Sb} 2,23)$

(226) $4,32-34$.

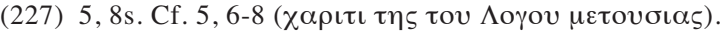

(228) Por la envidia del diablo entró la muerte al mundo (5, 11s; Sb 2, 24; cf. DI 5, 4s). 


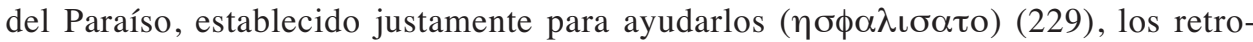
trajo a lo que les correspondía por naturaleza: salidos de la nada, soportar la corrupción hacia la nada (230). Y dominaba la muerte reinando sobre ellos (231). Y la

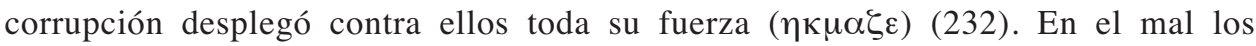
hombres sobrepasaron toda medida y fueron insaciables en el pecado (233). El género humano se destruía; el hombre razonable ( $\lambda$ оүькоऽ) hecho según la imagen, desaparecía, y la obra creada por Dios perecía (234).

¿Podía Dios, en su bondad, dejarlo simplemente perecer? Por un lado, no podía dejarse de cumplir la ley puesta por él mismo, a causa de la trasgresión (235). De no ser así, lo dicho por Dios sería mentira, si después de la trasgresión el hombre no moría. Dios no sería verídico $(\alpha \lambda \eta \theta \eta \varsigma)$. Por otro, no era digno de la bondad de Dios que lo creado por él pereciera o por negligencia de los hombres o por engaño del demonio.

(229) Cf. 3, 28-46. Porque la $\pi \rho 0 \alpha \iota \rho \varepsilon \sigma \iota \varsigma$ del hombre podía inclinarse a un lado o al otro. Esta ley iba con vida feliz, además de la promesa de incorruptibilidad en los cielos y amenaza de muerte y corrupción.

(230) Cf. 4, 21-23. Se dieron vuelta hacia la nada, abandonando al Dios que es (cf. 4, 25-29). La sentencia

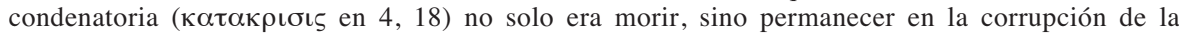
muerte $(3,44-46)$. Por la muerte se pasa a la $\delta \iota \alpha \lambda v \sigma ı \varsigma$ de la corrupción (cf. 4, 29s; véase $3,36 \mathrm{~s} ; 5$,

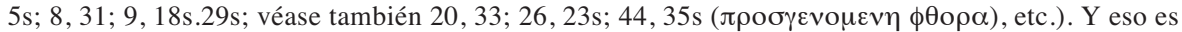
lo que teme el hombre, según 27, 8-11 (cf. 29, 21s). Cristo va a morir, pero es incorruptible. E1 cristiano tendrá $\delta \iota \alpha \lambda v \sigma ı \varsigma$, pero no corrupción, en espera de la resurrección (cf. 21, 4-17; véase 10, 48-51). Por eso los mártires no temerán a la muerte (cf. 27, 1ss). A Kannengiesser (ad 3, 44-46) le parece que "l'expression de Gen. 2, 17, $\theta \alpha \nu \alpha \tau \omega \alpha \pi \delta \theta \alpha v \varepsilon \iota \sigma \theta \varepsilon$ suggère dès ici la distinction entre

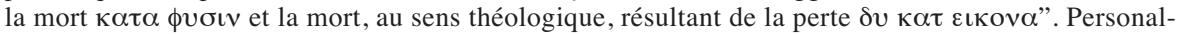
mente y sin excluir lo anterior, me inclino a que Atanasio lo interpreta como un intensivo de la muerte que se prolonga en corrupción (cf. también 21,3). En ese sentido, el dominio de la muerte y el de la corrupción es el mismo. Puede verse la nota respectiva a la traducción castellana de J. C. Fernández Sahelices, introducida por F. Guerrero Martínez (Atanasio, La encarnación del Verbo (Biblioteca de Patrística, 6), ed. Ciudad Nueva, $2^{a}$ ed., Madrid 1997). La traducción hipotética de Thomson ("having such a nature as not ever to exist") de 4, 23s, que defiende D. O'Brien (L'immortalité chez saint Athanase (De Incarnatione Verbi, cap. IV-V), en Studia Patristica 21 (Oxford 1987), pp. 426-437) contra la de Kannegiesser ("leur nature était autrefois le néant"), a mi parecer, no alteraría el fondo de la presentación que hago.

(231) $4,19 \mathrm{~s}$.

(232) 5, 13-16. Prevaleció contra la naturaleza, haciendo valer también contra ellos la amenaza divina por la trasgresión del mandamiento.

(233) Cf. 5, 17-24. A continuación en el número 4s, Atanasio trae un resumen del mal desatado. Véase también $8,12-14 ; 11,44 \mathrm{~s} ; 12,6 s .32-35$ (parecían irracionales, $\alpha \lambda \mathrm{o} \gamma \mathrm{o \iota}$ ). Los hombres, que participaban de la imagen del Padre, Nuestro Señor Jesucristo, para que pudieran conocer a Dios, se apartaron de Dios y tanto mancharon su alma, que no solo olvidaron la idea de Dios, sino que se entregaron a la idolatría y llegaron finalmente a dar culto a los demonios, etc. (11, 23-44). Así Atanasio retoma el tema de la idolatría del CG a propósito de la restauración de la imagen. Sobre el mal y su desarrollo, principalmente en el CG, puede verse, De Nicola, op. cit.

(234) 6, 2-5. En CG 3-8 explica más largamente esta caída que termina en la idolatría, centro de la refutación de esta obra. Los hombres se apartaron de la contemplación de Dios prefiriendo lo sensible, su propio cuerpo. Cayeron en el deseo del cuerpo. Se olvidaron de la $\delta v v \alpha \mu \iota \varsigma$ recibida de Dios. Y así aprendieron a asesinar y cometer injusticias (3). El alma fue seducida por el placer. Apartándose de la contemplación de los inteligibles, del bien (de lo que es), el alma, siempre en

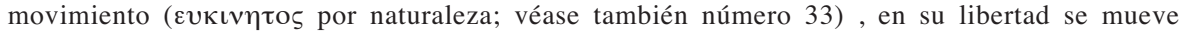
hacia el mal (lo que no es) (4). En el número 5 enumera diversos pecados que cometen los hombres. El mal no tiene subsistencia propia ni hay otro Dios, autor del mal (6s). El mal nació del alma humana que buscó lo corruptible; y del mal surgió la idolatría en cuyas supersticiones se hunde cada vez más el hombre $(7 \mathrm{~s})$.

(235) Véase también 8,8-11. El vocablo vouos es usado 5 veces en este sentido. 
Porque entonces, ¿cuál sería la utilidad $(\chi \rho \varepsilon \iota \alpha)$ de haberlos hecho? (236). Entonces habría sido mejor que ellos no llegaran a existir. Porque del hecho de haberlos creado, se concluiría más bien la debilidad de Dios que su bondad. Por tanto, era indigno de la bondad de Dios dejar perecer a los hombres en la corrupción. Sin embargo, era absurdo que Dios, el Padre de la verdad, pareciera mentiroso (237). Y no bastaba con que los hombres se arrepintieran para que pasaran a la incorruptibilidad. Si no morían, Dios no parecería verídico. Además, el arrepentimiento solo pone término a los pecados, pero no libera ( $\alpha \nu \alpha \kappa \alpha \lambda \varepsilon \iota \tau \alpha \iota)$ de las condiciones de la naturaleza. Porque los hombres, despojados de la gracia de ser según la imagen, estaban bajo el poder de la corrupción. Para restaurarlos ( $\alpha \nu \alpha \kappa \lambda \eta \sigma \iota \varsigma)$, en consecuencia, era necesario el Logos de Dios que creó el universo (238). Era propio de él conducir lo corruptible a la incorruptibilidad y preservar en todo lo que convenía al Padre. Era el único capaz de recrear el universo, de padecer por todos y ser un apropiado embajador (239) a nombre de todos delante del Padre. Por esto el Logos incorporal, incorruptible e inmaterial, por filantropía y compasión, sin dejar ninguna parte de la creación vacía de él y permaneciendo junto a su Padre, se encarnó para nuestra salvación (240). Esto era lo conveniente y necesario (241). Esta es la primera $\alpha \iota \tau \iota \alpha$ (242) de la Encarnación del Salvador. Pero también se encarnó por lo que va a seguir (243).

Porque tampoco Dios podía permitir que perecieran los hombres racionales ( $\lambda$ оүıкоı) creados según su imagen (con una idea de Dios). ¿Para qué los creó racionales? ¿Qué ventaja para el Dios creador, si ellos piensan que otros son sus creadores? (244) Pero ¿cómo renovar la imagen? Tenía que venir el mismo Logos de Dios, imagen del Padre, a recrear al hombre según la imagen (245). Por lo demás esto no podía ser si la muerte y la corrupción no eran aniquiladas. Luego, con toda razón, tomó el Logos un cuerpo mortal a fin de que la muerte pudiera ser aniquilada en él (246) y que los hombres fueran de nuevo renovados según la

(236) Véase también $8,18 \mathrm{~s} ; 11,11-16 ; 13,6 \mathrm{~s} .9 \mathrm{~s} .11 \mathrm{~s} .22$

(237) Cf. 6, 5-7, 5.

(238) En 1, 41-43, había dicho que no parecerá contradictorio si el Padre realiza la salvación mediante



(239) Según Camelot (ad 1. c.), esta imagen se asemeja a Cristo como abogado o intercesor.

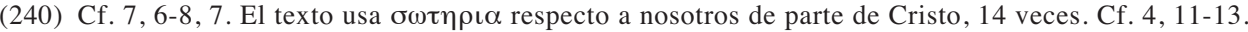
Respecto a la filantropía, cf. lo ya dicho sobre la bondad de Dios. Sobre la compasión, véase p. e. 8, 16. El $\alpha \gamma \alpha \pi \eta$ de Cristo por nosotros solo es nombrado en $10,15 \mathrm{~s}$ (cita de 2Co 5, 14), 16, 11s (cita de Ef 3,19) y en 52, 3s.

(241) En los números 6 y 7, en que trata del dilema de Dios entre su verdad y su bondad, a menudo usa

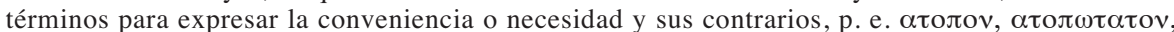

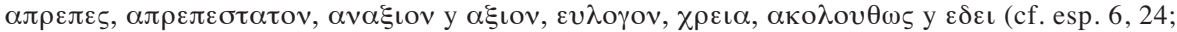
$7,6)$. Estos párrafos son solo una muestra de lo centrado que está Atanasio en este tipo de vocablos a través de esta obra, dado su tema. Recordemos que en la introducción de DI contra la calumnia de los judíos y la risa de los griegos Atanasio se ha propuesto mostrar la Encarnación

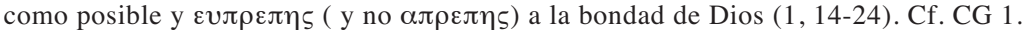

(242) Este vocablo, además de otros de significado parecido, es usado 5 veces respecto a la Encarnación y 2 directamente respecto a su muerte.

(243) $10,51-54$

(244) Cf. 13, 1-27. Según 11,11-16, ¿para qué los habría hecho Dios si no quisiera ser conocido por ellos? No diferirían de los irracionales.

(245) No podía ser por medio de ángeles, porque ellos no son imágenes (Kannengiesser, ad 1. c, remite a un texto antignóstico de Ireneo, Adv Haer, IV, 20, 1).

(246) Revistió un cuerpo para que, resucitado, permaneciera inmortal (44, 36-39), etc. 
imagen (247). Estas son, pues, la primera y segunda causa de la Encarnación que Atanasio expone. Me referiré a ellas por separado (248).

Pero muy conectado con la renovación de la imagen está el tema del conocimiento de Dios (249). Justamente perder la imagen es perder el conocimiento de Dios, volverse irracional; y por la renovación de ella, el hombre puede volver a conocerlo (250). Mas, dominando el culto a los ídolos y la impiedad, estaba oculto el conocimiento de Dios. ¿Quién podía, entonces, instruir sobre el Padre? Tenía que ser por lo visible. Se había visto que no bastaba con la creación. Luego, al mismo Logos que por su providencia y el orden de la creación enseña sobre el Padre, le correspondía renovar la enseñanza. Pero los hombres solo miraban hacia abajo. Dado que los hombres, habiéndose apartado de la contemplación de Dios, lo buscaban en los objetos sensibles, el Logos toma un cuerpo para atraer sobre él los sentidos de los hombres a fin de que, a través de sus obras, conozcan la verdad, y mediante él tomen en consideración al Padre (251). Justamente introduce Atanasio el tema de la renovación de la imagen junto con el conocimiento de Dios en el número 11; y en el 14, después de afirmar la venida de la misma imagen para renovarnos, pasa a la necesidad de las obras corporales de Cristo para llevarnos al conocimiento de Dios. Por tanto, dada esta implicación entre el tema de la imagen y el conocimiento de Dios, los trataré en el mismo apartado, como segunda causa de la Encarnación, dejando para después el profuso tema de las obras de Cristo, que se extienden hasta el presente y que abarcarían también las de su muerte y resurrección.

Respecto a la enumeración de las causas siguiendo el curso de la obra de Atanasio, este concluirá en 16, 23-28 (252) diciendo que de dos maneras mostró su filantropía el Salvador mediante su Encarnación: porque hizo desaparecer la muerte de entre nosotros y nos renovó, y siendo $\alpha \phi \alpha \nu \eta \varsigma$ e invisible, se mostró mediante las obras y se dio a conocer como el Logos del Padre, el $\eta \gamma \varepsilon \mu \omega \nu$ y rey del universo.

Y retomará en 20, 1-14: solo era del Salvador, que al comienzo había hecho el universo de la nada, transformar lo corruptible en incorruptibilidad; solo era de la Imagen del Padre, recrear al según la imagen; solo era de nuestro Señor Jesucristo, que es la vida misma, resucitar inmortal a un ser mortal; solo era del Logos ordenador del universo, que es el único Hijo unigénito y verdadero del Padre, el enseñar respecto al Padre y destruir el culto de los ídolos. Pero la razón principal de su venida era morir para pagar la deuda de todos. Concluirá en 32, 32-38: En los últimos tiempos tomó un cuerpo por la salvación de todos y, por una parte, enseñó a toda la tierra sobre el Padre; por otra, anuló la muerte y regaló a todos la incorruptibilidad por la promesa de la resurrección, resucitando su propio cuerpo como primicia de ella y exhibiéndolo

(247) $13,27-41$.

(248) Dentro del tema del renacimiento y recreación del alma según la imagen (en el bautismo) dice que vino para encontrar, mediante la remisión de los pecados, al hombre como perdido, y salvarlo (cita a Lc 19, 10) (14, 7-11). Cf. 15, 41s. Respecto a otras expresiones de su obra por nosotros, cf.

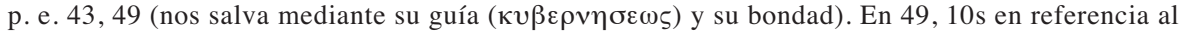
ciego de nacimiento y en comparación a la medicina de Asclepios, dice que no solo curó una herida sino plasmó el origen y restableció ( $\alpha \pi$

(249) Véase también lo dicho a propósito de la creación según la imagen.

(250) Sobre esto último, cf. 13, 29, etc.

(251) 14, 15-16, 28.

(252) Véase también 10,9-13. 
como un trofeo, contra la muerte y su corrupción, por el signo de la cruz. Y al final de la obra añadirá: Él se hizo hombre para que nosotros fuéramos hechos Dios ( $\theta \varepsilon$ oлoı$\eta \theta \omega \mu \varepsilon v)$ (253), él se manifestó a sí mismo mediante el cuerpo para que nosotros tuviéramos una idea del Padre invisible, y él soportó el ultraje de parte de los hombres para que nosotros heredáramos la incorruptibilidad (254).

\section{b) La victoria sobre la muerte y corrupción (255) (primera causa)}

Atanasio presenta esta primera causa de la Encarnación en los números 8 a 10, corroborándola en múltiples otros pasajes. Interpretando $\mathrm{Hb} 2,10$ dice que solo correspondía al Logos, que los había creado al comienzo, sacar ( $\alpha v \varepsilon v \varepsilon \gamma \kappa \varepsilon \iota v \alpha \pi 0)$ a los hombres de la corrupción (256). Dada la inderogable ley puesta por Dios, la corrupción solo podía ser eliminada muriendo (257). Aplicando esta todo su poder

(253) Única vez que emplea esta expresión aplicada a nosotros en esta obra. Según A. G. Hamman (L'homme, image de Dieu. Essai d'une anthropologie chrétienne dans l'Église des cinq premiers siècles (Relais-études, 2), Paris 1987, p. 153), "la divinisation de 1'homme est la véritable perspective de l'anthropologie d'Athanase, nulle part systématisée". Según Camelot (Contre les païens..., 96), "s'il est vrai de dire que l'homme est 'divinisé', on peut tout aussi bien dire qu'il est 'verbifié', qu'il est devenu tout entier 'logique'. Pour aller à Dieu, participer à sa connaissance et à sa vie, il n'y a pas d'autre voie que le Verbe incarné". "La divinisation est une conséquence de l'Incarnation; mieux, elle en est le but. L'Incarnation n'est pas seulement délivrance du péché et destruction de la mort (), elle est un renouvellement total de l'homme, à la ressemblance de l'image selon laquelle il avait été créé au commencement, elle est divinisation de notre nature" (ib., 93). Hamilton Hess (The place of Divinization in Athanasian Soteriology, en Studia Patristica 26 (Oxford 1991), 369-374) en un estudio más centrado en los vocablos concluye que 'divinización' no es el centro de la obra de Atanasio. Añade este autor (ib., 371): "By the incarnation itself he confers upon human nature the potential for restoration in his image. By his death and resurrection he destroys death, bestows immortality, suppresses corruption, atones for sin and conquers Satan. The restorative consequences for humanity are not automatic, however".

(254) 54, 13-17. Véase también 45, 1-6, etc. Comenta L. F. Mateo-Seco (Salvación y divinización (La lección de los Padres), ScrTheol 31 (1999) 453-469, p. 457): "La divinización del hombre tiene como centro nuestra unión con Cristo y, en consecuencia, es esencialmente referencia filial al Padre. En Cristo tiene lugar la divinización del hombre, incluida la incorruptibilidad que recibe en la resurrección de los cuerpos".

(255) Un simple vistazo al uso del término $\theta \alpha v \alpha \tau o s$ nos muestra la importancia de este tema y su dramaticidad. Es usado 184 veces. Si pudiéramos catalogarlas, alrededor de unas 41 veces tiende a aplicarse a la muerte enemiga que nos señorea, unas 71 veces a la muerte victoriosa del Señor, unas 59 veces a la muerte enemiga ya vencida por el Señor, y unas 13 veces a la muerte consecuentemente despreciada por los cristianos. La temible $\phi \theta 0 \rho \alpha$, que acompaña a la muerte enemiga y es consecuencia de ella, aparece 46 veces en nuestro texto. 4 veces se afirma que la $\phi \theta$ o $\rho \alpha$ es $\kappa \alpha \tau \alpha$ $\phi v \sigma ı v$ (el hombre ha perdido la gracia de escapar a la mortalidad natural). Por la $\phi \theta 0 \rho \alpha$ el hombre retornaba a la nada $(6,16 \mathrm{~s}$; cf. $4,22 \mathrm{~s})$. Por la $\phi \theta 0 \rho \alpha$ reinaba la muerte $(8,8)$. Cristo gustó la

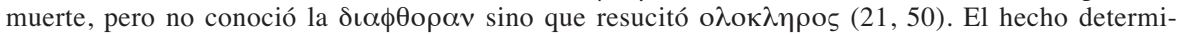
nante de la victoria contra la muerte es la resurrección. El solo vocablo $\alpha v \alpha \sigma \tau \alpha \sigma ı \varsigma$ es usado 48 veces, excluido 50, 34s. Es la resurrección del cuerpo, como la muerte era la muerte del cuerpo. Es resurrección de la vida (p. e. 10,43), que va con la incorruptibilidad (p. e. 9, 16s; 21, 12-15; 22, 24$27 ; 27,15 \mathrm{~s} ; 32,35 \mathrm{~s} ; 46,9 \mathrm{~s} ; 56,17 \mathrm{~s}$; véase $20,7 \mathrm{~s} ; 30,3-5 ; 44,38 \mathrm{~s}$ ). El cuerpo incorruptible de Cristo es primicia de la resurrección de todos $(20,20 \mathrm{~s}$; cf. 32, 35s). Así unas 10 veces apuntaría más directamente o se referiría a la resurrección final. La resurrección es una promesa, esperanza; una gracia. Obviamente su centro es la resurrección de Cristo y su testimonio.

(256) 10, 28-31. Para que no pereciera o se inutilizara la obra del Padre (8, 18s). Véase 7, 21-26.

(257) Cf. 8, 10s; 9, 1s. Según opinión de Schwager (op. cit., 390s), "Das Opfer am Kreuz bestand vielmehr darin, dass der Logos seinen Leib zur Verurteilung anbot, damit durch die Ausführung des Todesurteils die Forderung des Gesetzes erfüllt wurde... Von einer Opferden Tat des angenommenen Menschen ist beim Bischof von Alexandrien nirgends die Rede". 
en el cuerpo del Señor, en adelante no tendría más cabida contra sus semejantes, puesto que todos mueren en él (258). Por eso tomó un cuerpo para morir, el que, participando del Logos, llegara a ser apto para morir en vez de todos (259). Entregando su cuerpo a la muerte por todos $(\alpha \nu \tau \iota \pi \alpha \nu \tau \omega \nu)$, lo presentaba $(\pi \rho \circ \sigma \eta \gamma \varepsilon)$ al Padre (260). Lo ofrece como sacrificio, víctima sin mancha, haciendo desaparecer inmediatamente de todos los semejantes la muerte por la oblación del cuerpo semejante (261). Estando el Logos por sobre todos, al ofrecer su cuerpo como substituto ( $\alpha v \tau \iota \psi v \chi o v)$ por todos, con razón pagaba la deuda con su muerte (262). Atanasio corrobora con 2Co 5, 14: si uno murió por todos, entonces todos murieron (263). En beneficio de todo hombre gustó la muerte (264).

Después, en 20, 36-39, sintetizará así: La muerte de todos se cumplía en el cuerpo del Señor; y la muerte y la corrupción, por el Logos que le estaba unido ( $\sigma u v o v \tau \alpha)$, eran aniquiladas. Y proseguirá de esta manera: El Logos inmortal toma un cuerpo que pudiera morir, para ofrecerlo como propio a nombre de todos $(\alpha \nu \tau \iota$ $\pi \alpha \nu \tau \omega \nu)$ (265); y él mismo, padeciendo por todos por su entrada en este cuerpo, reduce a impotencia al diablo, que tenía el poder de la muerte, y libera a los esclavizados (266). Según 37, 55-59, toda la creación ha sido rescatada ( $\lambda \varepsilon \lambda v \tau \rho \omega \tau \alpha \iota)$ (267) con su muerte; él es la vida de todos y el que entregó en rescate ( $\alpha v \tau \iota \psi v \chi o v)$ su propio cuerpo a la muerte, como oveja, por la salvación de todos.

Volvamos a los números 8 a 10 en que estábamos, insistiendo ahora en la resurrección. Por nosotros murió y resucitó Cristo (268). Para retornar de nuevo a los hombres a la incorruptibilidad y vivificarlos a partir de la muerte, con la apropiación del cuerpo y la gracia de la resurrección, que hace desaparecer la muerte de

Sufre $(v \pi 0 \mu \varepsilon v \varepsilon \iota)$ por la inmortalidad y salvación de todos $(34,4)$. Padece por todos el que es la vida de todos (cf. 37, 15-18). Por la muerte alcanza la inmortalidad para todos (cf. 54, 9s). Véase $10,21 \mathrm{~s} ; 38,14$, etc.

(258) Cf. 8, 33-36. La ley de la corrupción quedaba derogada. Vino a consumar ( $\tau \varepsilon \lambda \varepsilon \iota \omega \sigma \alpha \iota)$, no su propia muerte sino la de los hombres, a destruirla completamente en su cuerpo (cf. 22, 11-18). En 34, 8-33, Atanasio trae la cita de Is 53, 3-10 sobre los sufrimientos y muerte de Cristo por nuestros pecados. Por sus llagas hemos sido curados, etc. Se dejó deshonrar para que nosotros fuéramos considerados. Y en 35, 8s, la cita de Jr 11, 19: como cordero inocente es conducido al sacrificio. Véase 36, 27-30; 37, 1-3. Comenta Camelot: "La mort de tous s'accomplit dans le corps du Seigneur" $(20,36)$. Ce n'est pas simple substitution d'une victime à une autre, c'est notre mort à nous qui mystérieusement s'accomplit dans le Christ à qui nous sommes unis par l'incarnation, et comme ce corps qui souffre et meurt sur la croix est le corps du Verbe, la mort et la corruption $(\phi \theta \circ \rho \alpha)$ sont détruites par sa mort" (Contre les païens..., 80).

(259) 9, 4-6. Cf. 7, 23-26. Véase 31,33-35.

(260) 8,32 .

(261) 9, 9-12. Cf. 10, 31-38 ( $\theta v \sigma \iota \alpha v)$. Cita Hb 2, 14s: con la muerte reduce a la impotencia al diablo que tenía el poder de la muerte y libera $\left(\alpha \pi \alpha \lambda \lambda \alpha \xi \eta_{\mathrm{t}}\right)$ a los esclavizados por el miedo a la muerte. Véase $10,9 \mathrm{~s} ; 25,44 ; 31,34$. Con el sacrificio $\left(\theta v \sigma \iota \alpha_{\mathrm{t}}\right)$ de su propio cuerpo puso fin a la ley contra nosotros $(10,38 \mathrm{~s})$. Según $16,18 \mathrm{~s}$, ofrecer $(\varepsilon \pi \iota \tau \varepsilon \lambda \varepsilon \omega)$ el sacrificio es entregar el cuerpo a la muerte y resucitarlo.

(262) 9, 12-15. Cf. 20, 12-19 ( $\alpha \nu \tau \iota ~ \pi \alpha \nu \tau \omega v$; así liberaba). 36-39.

(263) 10,16s. Al morir como maldito, tomaba sobre sí nuestra maldición (cf. 25, 6-10).

(264) 10,23 (Hb 2,9).

(265) A $v \tau \iota \pi \alpha \nu \tau \omega \nu$ es usado 5 veces.

(266) 20, 40-47, citando Hb 2, 14s. Véase $\varepsilon \xi \iota \lambda \alpha \sigma \alpha \sigma \theta \alpha \iota \tau \alpha \varsigma \alpha \delta \iota \kappa \iota \alpha \varsigma$ de Dn 9, 24 en 39, 13.

(267) Es rescate $(\lambda v \tau \rho o v)$ por todos $(25,11)$. Cf. 21,$49 ; 25,18 \mathrm{~s} ; 40,11 \mathrm{~s}$.

(268) Cf. 10, 18s, citando 2Co 5, 15 . Véase $21,1 \mathrm{ss}$, donde termina citando 1 Co 15, 53-55. 
entre ellos como la paja por el fuego (269). Así sucedió, por la Encarnación del Logos, la destrucción de la muerte y la resurrección de la vida: "Puesto que por un hombre vino la muerte, así por un hombre la resurrección de los muertos. Así como todos mueren en Adán, así también en Cristo todos serán vivificados" (1Co 15, 21s) (270). Ya no morimos como condenados, sino como despertándonos ( $\varepsilon \gamma \varepsilon \iota \rho о \mu \varepsilon v o \iota)$ esperamos la común resurrección de todos, que nos mostrará en su propio tiempo el Dios que obró y regaló esta (271). Porque Cristo, pese a la muerte, por el Logos que inhabitaba en él permanece incorruptible y en adelante cesa la corrupción de todos por la gracia de la resurrección (272). El incorruptible Hijo de Dios, unido (ovvwv) a todos los hombres por un cuerpo semejante, con razón revistió a todos de incorruptibilidad en la promesa de la resurrección. Porque la misma corrupción en la muerte, ya no tiene lugar contra los hombres a causa del Logos que inhabita en ellos mediante su cuerpo individual ( $\varepsilon v o \varsigma)$. Así como basta que el rey habite en una casa para que toda la ciudad quede dignificada y segura; así con la venida del rey del universo a habitar un cuerpo semejante a los nuestros, desapareció la corrupción (273). Renovó el principio de vida, dándonos la esperanza de la resurrección (274).

Así la muerte, según 27,1-16, está verdaderamente muerta (275), como testimonia el desprecio por ella de los discípulos de Cristo (276), que la pisotean y prefieren morir antes que renegar de su fe, porque saben que no perecen sino que viven y llegan a ser incorruptibles por la resurrección. Y en 29, 44-30, 3 concluye esta larga exposición de la victoria de los cristianos sobre la muerte: es Cristo el que ha abolido la muerte, y ha disuelto y hecho cesar su corrupción. Finalmente, en su segunda manifestación, no ya en bajeza sino en la propia gloria, no vendrá a

(269) Cf. 8, 36-41. Según 16, 24s, el Salvador hacía desaparecer la muerte y nos renovaba. Véase 26, 36s.

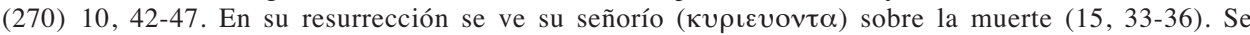
mostró más fuerte que la muerte, exhibiendo su propio cuerpo incorruptible, como primicia de la resurrección de todos $(20,19-21)$.

(271) 10, 48-51. Ya no morimos en la muerte, como en otro tiempo, porque esa condenación ha sido suprimida. La corrupción ha cesado y desaparecido por la gracia de la resurrección. En adelante nos disolvemos $(\delta \iota \alpha \lambda v o \mu \varepsilon \theta \alpha)$ según lo mortal del cuerpo solo durante el tiempo determinado por Dios para cada uno, para que podamos obtener una mejor resurrección. $\Delta \iota \alpha \lambda v o u \varepsilon v o \iota$, no perecemos, sino que como sembrados seremos resucitados, abrogada la muerte por la gracia del Salvador. Esto lo confirma con 1Co 15, 53-55: lo corruptible revestirá la incorruptibilidad, y lo mortal la inmortalidad; la muerte ha sido engullida en la victoria; ¿dónde está, oh muerte, tu aguijón? (21, 2-17). Cf. 27, 39s

(272) Cf. 9, 6-8. Aunque el cuerpo era mortal y le correspondía corromperse por naturaleza, estaba fuera de la corrupción por el Logos que inhabitaba en él (cf. 20, 31-34). Siendo la misma vida, resucita inmortal lo mortal $(20,7 \mathrm{~s})$; así, por el Logos ovvov $\alpha$, se aniquila la muerte y la corrupción (cf. 20,37s). Aunque murió como rescate ( $\lambda v \tau \rho o v)$ por todos, no vio la corrupción, sino que resucita intacto, porque era el cuerpo de la misma vida $(21,49-51)$. Era la vida de todos, la que aniquiló totalmente el poder de la muerte (cf. 24, 19-26). Véase 24, $12 \mathrm{~s}$.

(273) Cf. 9, 15-33. Había venido a poner un término a la muerte.

(274) 10,39 s (cf. 10, 49-51). No impidió la muerte para no impedir la resurrección (21, 43-45). Se preocupaba sobre todo de la resurrección del cuerpo, que iba a realizar. Era un trofeo contra la muerte, que iba a exhibir para convencer a todos de que la corrupción había sido suprimida por él, de que en adelante la incorruptibilidad de los cuerpos estaba adquirida, como garantía de la cual y como señal de la resurrección que habría para todos, había conservado su cuerpo incorrupto (cf. 22, 19-26). En su resurrección se mostraba el fin de la muerte, vaciada en adelante por la incorruptibilidad del cuerpo; la victoria contra ella (cf. 23, 29-32).

(275) Solo el diablo permaneció verdaderamente muerto (27, 17s). Cf. 23, 29-32.

(276) Ahora que el Salvador resucitó su cuerpo. 
padecer sino a retribuir a todos el fruto de la propia cruz: la resurrección y la incorruptibilidad (277).

Cristo, pues, pisoteó la muerte en su cuerpo y la abolió. Muerta la muerte por él, no quedaba sino resucitar su cuerpo (en adelante inmortal), siendo él la vida, y mostrarlo como trofeo contra ella (278). Y que está vivo, se ve por los efectos, que describe largamente (279). Convierte muchedumbres de griegos y bárbaros, enseña la inmortalidad y eleva los deseos a las cosas celestiales, destruye la idolatría y expulsa a los demonios. La magia cesa. Su sola presencia convierte en muertos a dioses y demonios. Es confesado por todos como Hijo de Dios, etc. El Hijo de Dios, viviente y actuante, día a día obra la salvación de todos y la muerte va perdiendo fuerzas (280), ya ha sido abolida (281). Volviendo al texto de 20, 32-38, notemos

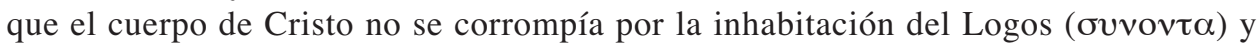
así destruía la muerte y la corrupción. Al resucitar, añadiríamos, se revestía de incorruptibilidad e inmortalidad (282).

Si el Logos tomó un cuerpo, cuerpo que era templo de la vida, este no podía permanecer en la muerte (283). Según 44, 23-45, 3, dado que la corrupción no era exterior al cuerpo, era necesario que la vida se entrelazara con él en lugar de la corrupción. Y como la muerte se había producido en el cuerpo, así también en él se realizara la vida (284). Era, pues, necesario, que la vida, en vez de la muerte, se entrelazara con el cuerpo, para que revestido de ella, a cambio ( $\alpha \nu \tau \varepsilon v \delta v \theta \varepsilon v)$, arrojara fuera la corrupción (285). El cuerpo de Cristo, entrelazado a la vida, ya no permanecería en la muerte, sino que revestido de inmortalidad, resucitado, permanecería inmortal. Por esto el Logos se revistió de un cuerpo, para encontrar a la muerte en el cuerpo y hacerla desaparecer (286).

Pero retomemos el tema de la muerte, bajo la noción de la cruz. Porque ella es la ignominiosa muerte en cruz (287). Ya al comienzo del DI, ante las calumnias de los judíos y las irrisiones de los griegos por la manifestación del Logos, afirma Atanasio que Cristo destruye la ilusión de los ídolos con su pretendida bajeza mediante la cruz (288). En 19, 12-20, vuelve a aparecer la cruz, como trofeo contra la

(277) $56,12-18$.

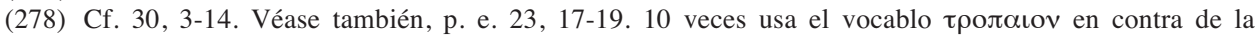
muerte. La victoria de Cristo contra la muerte es expresada con el sustantivo vıкๆ 8 veces; con vıкоร, 2 (1Co 15, 55); y 4 veces con el verbo vıк $\alpha \omega$. Trofeo de la victoria contra la muerte, según 26, 10-12, es la incorruptibilidad y $\alpha \pi \alpha \theta \varepsilon\llcorner\alpha$ producida en el cuerpo por la resurrección (véase 46, 7-10).

(279) $30,17-32,30$.

(280) $31,22-24$.

(281) $40,54 \mathrm{~s}$, etc. De muchas maneras y repetidas veces expresa la destrucción de la muerte y la corrupción.

(282) El cuerpo incorrupto se convertía en incorruptible. Es verdad que la resurrección, p. e. en la resurrección final, puede resucitar cuerpos corrompidos y esto es lo que dice de paso respecto a una excluida posibilidad del cuerpo de Cristo en un desarrollo retórico (cf. 26, 23-25).

(283) Cf. 31, 29-38.

(284) La vida de suyo vence a la muerte, pero es necesario que esto suceda en el cuerpo, donde estaba la muerte (cf. 44, 32-36).

(285) Una vez revestido de la corrupción, no podía resucitar si no se revestía de la vida. Véase 26, 9s.

(286) Vivificando lo mortal, se mostraba como vida.

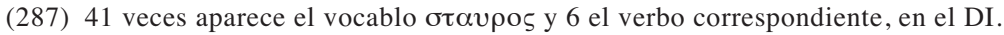

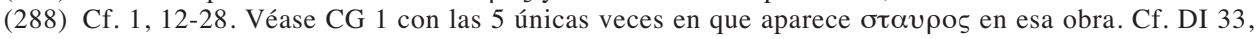
$6 \mathrm{~s}$. Véase $50,10 \mathrm{~s} ; 53,14-16$. 
muerte (289). Toda la creación lo confiesa como Hijo de Dios y Salvador, como el

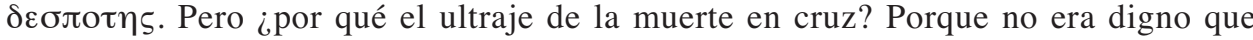
muriera por debilidad natural, siendo el poder de Dios y la vida misma. No convenía que enfermara el que curaba las enfermedades. Así como, siendo la vida, no convenía que se diera la muerte a sí mismo, tampoco convenía que huyera de la muerte dada por otros, ya que él mismo la buscaba para destruirla. Y su muerte tenía que ser pública para que pudiera ser testimoniada su resurrección (290). Si no huyó de las deshonra de la cruz, fue para mostrar su poder contra cualquier tipo de muerte que le impusieran (291). Hasta aquí las principales razones en pro de la cruz contra los objetores externos. Atanasio, volviéndose ahora a los nuestros, agrega las siguientes consideraciones para que el Salvador soportara la cruz (292). El vino para llevar sobre sí nuestra maldición, y maldito es el que está suspendido en un madero (293). Solo en la cruz se muere con las manos extendidas, así atrae con una al antiguo pueblo y con la otra a los gentiles para unir a ambos en él (294). Solo en la cruz se muere en el aire, así purifica el aire de los demonios (295) y restablece el camino que sube al cielo (296). Por tanto, con el testimonio extraordinario de la creación sobre la parusía de su demiurgo (al morir Cristo), concluye Atanasio que era conveniente la muerte en la cruz para nuestra salvación (297). Nuestro autor continuará en su obra afirmando la victoria de la cruz contra la muerte (298). Los cristianos pisotean la muerte con el signo de la cruz (299). Con este signo cesa toda magia, etc., y todo hombre levanta la vista al cielo (300). Él persuadió a los bárbaros y paganos; dio seguridad de inmortalidad (301). Así el Salvador crucificado (302) es proclamado en toda la tierra Dios e Hijo de Dios (303). La cruz ya había sido anunciada por Moisés y los profetas (304).

Después de esta avalancha, no exhaustiva, de textos bastante repetitivos sobre la primera causa, presentados con algún orden, pero que dejara traslucir el vigor y sabor del lenguaje atanasiano, me atrevo a intentar alguna síntesis reflexiva. Me atrevería a afirmar que la concepción de Atanasio sobre nuestra redención se centra en el cuerpo de Cristo. Por su cuerpo individual, que es semejante (aspecto muy

(289) Véase también 24, 27s; 45, 28-30 (contra principados y poderes, como en Col 2, 15)

(290) Cf. 21, 20-24, 5.

(291) Cf. 24, 5-32.

(292) Cf. 25, 1-45.

(293) Cf. Ga 3, 13; Dt 21, 23.

(294) Cf. Ef 2, 14; Jn 12, 32.

(295) Satanás cae.

(296) Cf. Ef 2, 2; Lc 10, 18;Hb 10, 20; Sal 23, 7.

(297) Cf. 26, 1-7. Véase 37, 53-55. Para mostrar que su cuerpo estuvo muerto, solo lo resucitó al tercer día. Y no más, para no resucitar un cuerpo en plena descomposición, que pudiera creerse ser otro diferente $(26,12-35)$.

(298) $27,1-3 ; 30,1-3$. Véase $27,33-35 ; 29,8-10 ; 32,36-38$. Cf. CG 1. El fruto de la cruz es la resurrección y la incorruptibilidad ( $56,16-18)$.

(299) 27,7 s. Cf. 28, 6-9; 29, 1s.14-17.31-34.

(300) $31,14-18$. Cf. 47, 12-14; 48, 7-13; 53, 17s; 55, 7-9. Véase 48, 26-30.

(301) 50, 28-33.

(302) Señor de la Gloria $(53,34$ s, en cita de 1 Co 2,8$)$.

(303) $53,18-20$.

(304) 35, 1-18 (Dt 28, 66; Jr 11, 19; Sal 21, 17-19). Cf. 34, 1-33 (Is 53, 3-10). Véase 36, 27-30; 37, 1-3; 38,10 s. 
insistido), el Salvador está conectado con todos y se extiende a todos (305), gracias a que es el cuerpo del Logos Dios (306). En él está la vida de todos. Todos mueren en su muerte y resucitarán en su resurrección (307). Este 'todos', tan repetido, no implica que todos se vayan a salvar. Así Cristo en su segunda manifestación juzgará a todos según las obras de cada uno; y a los que obran el mal les está reservado el fuego eterno (308). Ese 'todos' es el de la victoria de Cristo en la cruz frente a la muerte y corrupción, en un duro ataque a judíos y griegos. ¿Cómo ocurre esta redención por el cuerpo de Cristo? Gracias a su muerte y resurrección. Lo dice de variadas maneras. Quizás la principal sea la de la vida. El Logos es la vida (309), y la vida desplaza (310) a la muerte, hace cesar la corrupción. La corrupción no es exterior sino que está incrustada en el cuerpo y la vida la expulsa. La vida es la que conserva incorrupto el cuerpo de Jesús y lo resucita incorruptible e inmortal (311). Para el desplazamiento se necesita que la vida se encuentre con la muerte, y esto es lo que acontece en la muerte de Jesús. Esta explicación engloba la muerte y resurrección. Pero hay otra explicación directa respecto a la necesidad de la muerte de Cristo: es la de la deuda que va anexa a la trasgresión de la ley del paraíso. Cristo paga el rescate a nombre de todos (312). ¿Cómo lo paga? Ofreciendo a la muerte su cuerpo en sacrificio a nombre de todos. O, dicho de otra manera, dejando que la muerte y corrupción ejerzan sobre él todo su poder y ya no puedan seguir con los demás (313). Estos serían los dos principales modos de explicación. Si en el problema del conocimiento todo se dirige a tener una idea del Padre a través del Logos, en esta explicaciones, Dios, el Padre, prácticamente no aparece (314). Por otro lado, aunque la muerte entró por una trasgresión $(\pi \alpha \rho \alpha \beta \alpha \sigma \iota \varsigma)$, en referencia a la salvación no se habla, en general, de $\alpha \mu \alpha \rho \tau \iota \alpha$ (315). En resumen, la salvación nos viene por el cuerpo muerto de Cristo, y resucitado como primicia. Por eso el Logos se encarnó (tomó cuerpo). Llama la atención lo corporal de esta concepción. Pasemos a otros aspectos. Solo el Logos, que lo había creado, podía transformar el cuerpo

(305) Cf. 44, 21s. Según 54, 9s, por la muerte la inmortalidad llegó a todos. Según 37, 55s, por su muerte toda la creación fue rescatada (cf. 45, 26-31). Véase 16, 13-17; 29, 10ss; 45, 32-34. Puede verse L. Bouyer, L'Incarnation et l'Église-Corps du Christ dans la théologie de saint Athanase (Unam Sanctam, 11), Paris 1943, cap. III, 1.

(306) Vease Galtier, op . cit., 557-563. "Mais le vrai secret de l'incorporation, par laquelle il est plus que notre frère, à savoir notre chef, repose sur sa divinité et sur la place unique qu'il occupe, en tant que Verbe, par rapport à toutes les oeuvres de Dieu" (J. Roldanus, Le Christ et l'homme dans la théologie d'Athanase d'Alexandrie. Étude de la conjonction de sa conception de l'homme avec sa christologie (Studies in the History of Christian Thought, 4), Leiden 1977, p. 355s).

(307) Contrapuesto una vez a Adán, por el que entró la muerte.

(308) $56,16-32 ; 57,18-20$.

(309) Véase lo dicho antes hacia el final de la parte El Logos y el Padre.

(310) Digo desplazamiento (desaparición, desvanecimiento), como el sol expulsa las tinieblas (29, 1018) o la presencia del rey en la ciudad mantiene alejados a los enemigos; o destrucción, como el fuego destruye la paja.

(311) La vida no podía permanecer en la muerte.

(312) Y libera a los esclavizados al diablo.

(313) Ya todos murieron en él.

(314) Explícitamente, solo se habla de una presentación de Cristo ante el Padre y de una embajada.

(315) Salvo dos veces y en las citas de Is 53 (34, 10.13.19). Las dos veces son: vino a encontrar el hombre perdido mediante la remisión de los pecados (cf. 14, 8s); profetizaban hasta que viniera la misma justicia y el que rescata $(\lambda v \tau \rho o v \mu \varepsilon v o \varsigma)$ los pecados de todos $(40,11 \mathrm{~s})$. 
corruptible en incorruptible. Es evidente que está resucitado por las obras maravillosas que realiza actualmente, que demuestran que la muerte está muerta y que la corrupción ha cesado. Es la victoria de la cruz. Los cristianos, que pisotean la muerte, no tendrán corrupción sino disolución en espera, como semillas, de la resurrección.

\section{c) La reconstitución de la imagen y el conocimiento de Dios (segunda causa)}

Como ya vimos en la reacción de Dios a la situación del hombre, Dios tampoco podía permitir que perecieran los hombres creados según su imagen. Tenía que renovarlos para que los hombres, a través de esto, de nuevo pudieran conocerlo. La misma Imagen del Padre tenía que venir a renovar al hombre. Tomó, pues, un cuerpo, no solo para aniquilar la muerte y corrupción (condición de lo que sigue a continuación (316)), sino para recrear según la imagen (317), lo que podría equivaler al $\theta \varepsilon о \pi о \imath \eta \theta \omega \mu \varepsilon v$ de 54,14 , en la última enumeración de las causas de la encarnación. Esto haría sentido con lo dicho a propósito de la creación del hombre. Según lo visto ahí, renovar la imagen es volver a reproducir ( $\alpha v \alpha \tau v \pi o v \tau \alpha \iota)$ en el hombre la $\mu о \rho \phi \eta$ primigenia de este, conforme al Logos e Hijo, imagen del Padre (318). Atanasio anota de paso que esto es el reencontrar al perdido, por la remisión de los pecados, es el renacer y recrear el alma según la imagen, de lo que hablaba Jesús en Jn 3, 3 ( $\alpha$ $\alpha \gamma \varepsilon v v \eta \theta \eta$ ) (319).

Respecto al conocimiento de Dios, siguiendo con lo ya dicho al final de la creación del hombre sobre esto, Atanasio en el DI, contrariamente al CG, apenas alude a la contemplación del Logos (y al consecuente descubrimiento del Padre mediante él) en el espejo del alma que conserva en toda su pureza el ser imagen. El CG no entraba en la encarnación y llamaba a la purificación del alma para conocer a Dios. Pero en el DI el conocimiento del Logos invisible es por sus obras (320). Porque el hombre ya no miraba al cielo para conocerlo por el orden de la creación, Dios dio a los hombres las Escrituras, la ley y los profetas. Pero como esto tampoco bastó, el mismo Logos se dio a conocer por las obras de su cuerpo. Ya antes, a propósito del Hijo y el Padre, habíamos visto que el Hijo es el que da a conocer al Padre. Y en el tema de la reacción de Dios a nuestra situación se decía que es al Logos, que enseña al Padre por la creación, a quien correspondía renovar la enseñanza. Y por eso toma un cuerpo que atraiga los sentidos de los hombres.

Hasta aquí lo ya visto. Complementemos ahora un poco estos temas, siguiendo los principales textos de Atanasio con sus reiteraciones. Tratando el DI de la encarnación, Atanasio ha pasado del conocimiento de Dios por el alma en el CG a la

(316) Ambos motivos, como ha aparecido, van conectados, tanto en la caída como en la salvación. Cf. p. e. $4,32-34$ y $13,34-37$.

(317) Cf. 13, 27-41.

(318) “L’humanité ne pouvait être sauvée, arrachée à l'erreur et à la corruption du péché et de la mort que si elle était de nouveau divinisée, et cela ne pouvait se faire que si le Verbe, image du Père, se faisait homme pour réintroduire au coeur même de l'humanité la divine ressemblance, divinisant l'homme en l'unissant à sa divinité" (Camelot, Contre les païens, $94 \mathrm{~s}$ ).

(319) Cf. 14, 1-15.

(320) Es propio de Dios ser invisible, pero ser conocido por sus obras (32, 2-4; cf. 54, 1-3; véase 11, 1 9: diferencia en Creador y creatura, entre incorporal y corporal). 
salvación por el cuerpo de Cristo. Si poco se dice sobre el modo de renovación de la imagen en el hombre, salvo el hecho de que el Logos toma un cuerpo (321), mucho habla nuestro autor del conocimiento del Logos (y del Padre) por las obras de su cuerpo, tema, por lo demás, también típico de la encarnación. Creemos que Atanasio, al saltarse el alma de Cristo, no puede profundizar la renovación de la imagen en el hombre (322), salvo presentar al Logos-imagen en el cuerpo de Cristo. Por eso, en parte, seguiría el camino del conocimiento de Dios por las obras, al que paso ahora (323).

El Logos, como buen maestro, abajándose al nivel de los hombres los educa con cosas más simples. Como los hombres buscaban a Dios en la creación sensible, el Salvador atrae con su cuerpo sus sentidos para que a partir de las obras de su cuerpo conozcan la verdad y consideren al Padre. Donde aplicaren sus sentidos, se sentirían atraídos y aprenderían la verdad. Si estaban estupefactos ante la creación, la veían confesar a Cristo Señor. Si se inclinaban a los hombres hasta considerarlos dioses, comparando sus obras con las del Salvador, solo este aparecería como Hijo de Dios. Si atraídos por los demonios, los veían expulsados por el Señor. Si su pensamiento estaba poseído por los muertos dando culto a los héroes, en la resurrección del Salvador veían que él era el verdadero Señor. Por esto nació, se manifestó como hombre, murió y resucitó, embotando y oscureciendo con sus obras todo lo hecho por los hombres, para, desde cualquier parte adonde estos fueran atraídos, reconducirlos y enseñarles su verdadero Padre (324).

Porque, dado que el pensamiento de los hombres había caído en lo sensible, el Logos se abajó ( $v \pi \varepsilon \beta \alpha \lambda \varepsilon v)$ a manifestarse a través de un cuerpo para atraer

(321) Unas 7 veces habla de la renovación o recreación de la imagen en el hombre y siempre repite lo mismo, la venida del Logos (Jesucristo), imagen del Padre (cf. 13, 28-14, 9; 20, 5-7).

(322) El alma de Cristo habría servido de puente. Recordemos que, según 14, 14s, el alma humana es la que es recreada según la imagen.

(323) "L'incarnation restaure l'image de Dieu en l'homme, car elle lui donne de connaître le Logos même de Dieu. Comme Origène autrefois, Athanase joue sur le mot de 'raisonnable' (logikos) au sens d'une participation au Logos. Car le Verbe de Dieu est "l'Image" par excellence du Père. Le salut apparaît ainsi comme un renouvellement de l'être "à l'image de Dieu" qui est le fait des hommes, par la connaissance du Verbe, lui-même propre Image de Dieu" (B. Sesboüé, Christologíe et sotériologie. Éphèse et Chalcédoine (IV $-V^{e}$ siècles), p. 352, en B. Sesboüé y J. Wolinski, Le Dieu du salut (Histoire des Dogmes, I), Desclée 1994, pp. 341-416). "On a vu que l'incarnation restaure également en lui la connaissance de Dieu, puisque c'est dans et par cette connaissance que s'accomplit en nous l'image et la ressemblance de Dieu" (ib., 355s). Según Bernard (op. cit., 145), "l'effet principal du kat eikona pour le vous humain était l'illumination,

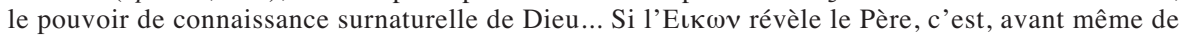

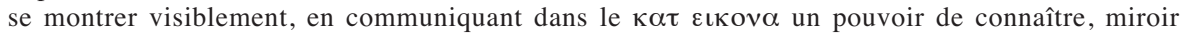
indispensable pour voir l'Image et en elle le Père".

(324) Cf. 15, 1-42.

(325) Kannengiesser dice al respecto (ad 1. c.): "L'incarnation du Logos modifie de fond en comble le statut de l'epistémologie théologique fondée sur la notion biblique de $\kappa \alpha \tau \varepsilon \iota \kappa o v \alpha$. La médiation des sens, bien loin de constituer une infirmité de l'esprit humain ou une simple démarche préliminaire dans la saisie salvatrice du Logos, devient le mode par excellence de cette saisie, le Logos ne se laissant connaître en vérité qu'à travers sa manifestation corporelle. Ainsi passe-t-on du plan de l'intuition intellectuelle, magnifiée dans le commentaire philosophique du chap. $1^{\text {er }}$ sur Gen. 1, 26-27, au plan de la foi, le seul où l'homme devient susceptible d'atteindre son unité totale". En p. 151s, había dicho este autor: "Le Logos-Eikôn vient en personne produire dans la condition corporelle des hommes les effets que produisait en l'âme d'Adam l'extase originelle du

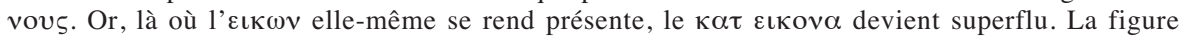


hacia él los sentidos de los hombres (325) y persuadirlos, mediante sus obras que él no era solo hombre sino también Dios. Atanasio, después de citar Ef 3, 17-19, añade que el Logos se despliega (326) por todas partes, arriba en la creación, abajo en la $\varepsilon v \alpha v \theta \rho \omega \pi \eta \sigma \iota s$, en la profundidad en el Hades, y en la anchura en el cosmos, y todo está lleno del conocimiento de Dios (327).

En el número 45,1-36, retoma la idea de que el Logos está y se da a conocer en todo; toda la tierra se llenó del conocimiento del Señor (Is 11,9). Como el Logos se da a conocer en la creación por sus obras, así tomó un cuerpo para obrar como hombre y mostrarse por todas partes no dejando nada vacío de su divinidad y de su conocimiento. Si alguien quiere mirar al cielo, verá el orden. Si no puede hacerlo sino solo levanta la vista hacia los hombres, por sus obras lo conocerá como el único Dios Logos. Si se torna hacia los demonios, verá que los expulsa

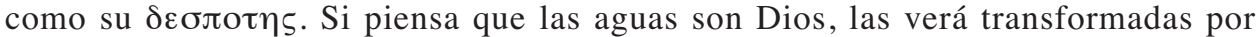
su Creador. Si desciende al Hades verá su resurrección y su victoria contra la muerte, como verdadero Dios. Porque el Señor tocó todas las partes del universo y las liberó de todo engaño para que en todas ellas se encuentre al verdadero Logos de Dios. Así se ve desplegada sobre la tierra la divinidad del Logos para que se adore solo a él y a través de él se conozca bien al Padre (328).

Solo el hombre erraba respecto al conocimiento de Dios. Como no podía reconocerlo en su conducción y gobierno del universo, el Logos toma un cuerpo, una parte del todo. Así el hombre, que no podía levantar la vista a su potencia invisible, podría comprenderlo y contemplarlo a partir de un ser semejante, y por sus obras divinas conocer más rápidamente y más de cerca al Padre (329). Por eso, una vez venido, no realizó inmediatamente el sacrifico y la resurrección, haciéndose así invisible, sino que se establecía visible permaneciendo en el cuerpo y realizando obras y signos que lo daban a conocer, no como hombre sino como Dios Logos (330). Como el Logos, siendo invisible, es conocido por las obras de la creación, así llegado a ser hombre y aunque no se lo ve en el cuerpo, sería conocido, como poder de Dios y Logos, por sus obras (331). Parecía bueno que el Salvador hiciera todas estas cosas para que los hombres, que habían desconocido su providencia universal y no reconocido su divinidad por la creación, por las obras de su cuerpo vuelvan a

d'une réalité n'a plus sa raison d'être, si cette réalité elle-même est donnée. C'est le cas de l'être humain du Logos incarné....A l'instar du vous originel, mais selon un accomplissement beaucoup plus conforme à notre vraie nature, ce Logos incarné devient la source et le lieu unique de la divinisation des hommes". Pueden verse las críticas de G. C. Stead a lo que afirma Kannengiesser sobre el alma y el vous del hombre y de Cristo (op. cit., pp. 388-390). Cf. 40, 8-10 donde se refiere al actual fin de la visión y del profeta en el judaísmo: "Pues viniendo lo significado, ¿qué necesidad habría aún de los signos? Haciéndose presente la Verdad, ¿qué necesidad habría aún de la sombra?".

(326) Cf. también 45, 31-34; 11, 47-49. Véase 44, 21s.

(327) Cf. 16, 1-17.

(328) Respecto a esto último puede verse también 46, 22-24.36-38; 55, 34-39, etc. Confirmando lo visto al comienzo sobre el conocimiento del Padre mediante el Hijo, podría precisar ahora que a través de él se tiene una Evvol $\alpha$ del Padre (cf. 11, 21s; 19, 4-6; 54, 14s; véase 11,3s; 15, 16-18). Solo Cristo es reconocido como Dios Logos (47, 18-20), etc.

(329) Cf. 43, 13-34.

(330) Cf. 16, 17-23. Véase 20, 15; 43, 33s; 54, 3-7, etc.

(331) $18,17-21$. Cf. 16, 23-28; 18, 11-17, etc. 


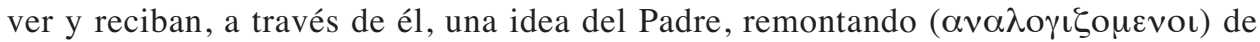
lo parcial a la providencia universal (332). Pero, como ya vimos, Cristo también se hace conocer como Dios, por la muerte de su cuerpo (333). Asimismo, las obras actuales testimonian cada día que resucitó y que es el verdadero Hijo de Dios (334). El Cristo resucitado, pues, revela actualmente el conocimiento del Padre (335). Cristo es el gran $\delta \iota \delta \alpha \sigma \kappa \alpha \lambda$ os que vino a enseñar sobre el Padre (336). Así Cristo ha llenado toda la tierra con su enseñanza (337).

Resumiendo estas repetitivas ideas de Atanasio en el tema del conocimiento de Dios, nuestro autor parece como deslumbrado por el resplandor del Logos (338) que se manifiesta por doquier. Dado que la obra está centrada en la Encarnación, se destaca el conocimiento por las obras del cuerpo de Cristo, aunque a menudo en paralelo y contraste (por la situación del hombre) con la creación y su orden. Por la idolatría el hombre buscó a Dios en lo sensible, y en esto justamente encuentra al Logos encorporizado, que vino a buscar y salvar al que estaba perdido. Arrumbando el tema de la contemplación de Dios mediante la imagen del alma (CG), presupone que el Dios invisible se da a conocer por sus obras visibles (339). Y gran tarea del Logos es la enseñanza del Padre, a quien se lo concibe a través de él.

Este abundante tema del conocimiento es, por lo menos, complementario con el de la recreación del hombre según la imagen. En el paraíso el uno se explicaba por el otro. Ambos se perdieron por la trasgresión del hombre, pero se recuperan por el cuerpo del Logos. Y el conocimiento por las obras del cuerpo, ha desplazado en gran medida al conocimiento por la imagen del alma. La imagen reconstituida es el Logos, que es la imagen del Padre, en cuerpo. El no describir más concretamente la renovación de la imagen, me parece que se debe en buena parte a que Atanasio se salta el alma de Cristo. La encarnación es tomar un cuerpo. Nos interesa ahora preguntarnos por las obras del Logos, a través de las cuales conocemos su divinidad y al Padre. De ellas haré a continuación una somera presentación. Respecto a las dos causas de la encarnación que presenta Atanasio, ellas obviamente se condicionan entre sí. Por alejarse de la contemplación de Dios se perdió la imagen y se cayó en la corrupción natural. Es claro que un hombre sujeto a la corrupción no puede ser

(332) 19, 1-7. Cf. 54, 10-13. Véase 19, 20s. Y al revés, si el Logos es conocido por las obras del universo, también debe serlo por las obras de un cuerpo que es parte del universo (Cf. 41, 12-42, 47; 43, 34-37).

(333) Cf. 19, 23-28. Véase, p. e., los prodigios que acompañaron su muerte (cf. 19, 11-20; 26, 6s; 49, 20-23).

(334) Cf. 32, 28-32. Véase 32, 4ss, etc.

(335) Cf. $31,9$.

(336) Cf. $14,17 \mathrm{~s} .34-36 ; 15,40 \mathrm{~s} ; 20,9-12 ; 32,32-34 ; 40,66 \mathrm{~s}$. Diecisiete veces se habla de su $\delta ı \delta \alpha \sigma \kappa \alpha-$ $\lambda \iota \alpha$, que no solo concierne el pasado sino sobre todo la actualidad, como un solo continuo. Trece veces se le aplica el verbo $\delta\llcorner\delta \alpha \sigma \kappa \omega$ y una $\delta\llcorner\delta \alpha \sigma \kappa \alpha \lambda$ os. Invisiblemente día a día persuade de su doctrina una multitud de griegos y bárbaros $(30,22-26)$. Cf. 1, 26-28;16, 5-7; 31, 6-11; 46, 34-38; 47, 31-37; 50, 28-33; 51, 16-20. También le aplica $\pi \alpha \iota \delta \varepsilon v \omega(15,3 \mathrm{~s} ; 50,6-9$; véase 34, 14).

(337) 48, 17s. Cf. 40, 60-67; 49, 26-28.32-34; 50, 4-9.15-21 (eclipsó a los sofistas), etc.

(338) Cf.p.e. 40,65s; 54, 33-35; 55, 15-20. Véase 40, 47-49; CG 1.

(339) Ahora podemos conocer al Logos por la semejanza (respecto a nosotros) de su cuerpo (cf. 14,4147; 43, 23-33). Con todo, exhorta, al final, a la purificación del alma para poder comprender 1o revelado en las Escrituras, en cuanto es posible a la naturaleza humana comprender al Logos de Dios (según texto crítico que trae Kannengiesser, aunque no lo traduce al francés). Solo el casi semejante puede ver lo deseado $(57,1-18)$. 
según la imagen del Dios eterno e incorruptible. Por eso que ambas dimensiones en Cristo se recuperan a la vez. Si fundamental es la victoria sobre la muerte (primera y principal causa), largamente insiste Atanasio en el tema del conocimiento de Dios en esta obra "apologética" (340). Más aún, la victoria sobre la muerte es una forma fundamental de darse a conocer. Por otro lado, el conocimiento, extendido por toda la tierra habitada, muestra también la gran victoria en la lucha contra la muerte. Ambos temas, pues, están entrelazados y así aparecerán a propósito de las obras del Logos.

\section{d) Las obras de Cristo}

Durante todo este trabajo han ido apareciendo las obras del Logos, que lo dan a conocer. Así, por ejemplo, a propósito de la creación, especialmente de la creación del hombre y su conocimiento de Dios; a propósito de los efectos victoriosos de su muerte y resurrección, que muestran que está vivo y que la muerte, que es despreciada por los cristianos, está muerta; a propósito de la recreación del hombre según la imagen y el respectivo conocimiento de Dios. Es constante el tema de la creación como obra del Logos, donde resplandece el orden y la armonía y se muestra su providencia. Diría que es como un telón de fondo respecto al primer plano: las obras del Logos por su cuerpo y las de después de resucitado (341). Atanasio entra poco en el detalle de las obras de la vida de Cristo, o de su Pasión (342), aunque insiste mucho en que sus obras no eran de un hombre cualquiera sino mostraban al Logos Dios. Gran obra es su muerte y resurrección (343). Su muerte fue pública, justamente para que el testimonio de su resurrección fuera con $\pi \alpha \rho \rho \eta \sigma \iota \alpha$ (344). Pero Atanasio no destaca el testimonio de los que lo vieron resucitado sino la victoria, que llega hasta él, consecuencia de la resurrección. Esto es lo visto hasta ahora, sobre lo que no volveré, sino que lo complementaré con lo que dice nuestro autor a partir del número 33 en su polémica contra judíos y griegos.

(340) Cf. 24, 1s.

(341) Cf. 49, 23-25. Véase 20, 14-16. Así el Logos, que actúa cada día, va invisiblemente persuadiendo $(30,22-26)$. Cf. 1, 26-28; 29, 17-20; 30, 29-31; 31, 6ss.22s; 32, 28s; 51, 16-20; 53, 8ss. Respecto al conocimiento por las obras, si nos fijamos solamente en el uso del vocablo $\varepsilon \rho \gamma o v$, este estaría referido unas 24 veces a las obras de Cristo por su cuerpo, unas 6 a las de Cristo después de resucitado y al menos unas 4 al conocimiento del Logos por las obras de la creación.

(342) Cf. 18, 1-51; 19, 7-21;23, 14-17; 25, 15s; 35, 12s.17s; 37, 1-3; 38, 11.20-48; 45, 17-21; 49, 1-24,


$\pi \alpha \sigma \chi \varepsilon \iota v 6$ veces, más $2 \pi \alpha \theta \eta \mu \alpha$ de $\mathrm{Hb}$ y $1 \pi \alpha \theta$ os), el que fue herido $(36,29 \mathrm{~s})$, etc. En 8 , $1 \mathrm{ss}$ contrapone las obras humanas de Cristo, que lo mostraban como verdadero hombre, a las divinas que lo mostraban como Dios, creador.

(343) Véase p. e. 19, 22-28. Según Ch. Kannengiesser, "Le mystère pascal du Christ prend pour les croyants et les hommes appelés à croire dans l'histoire complète de l'humanité la signification béatifiante qui avait été celle du Logos contemplé en soi par les premiers humains. C'est pourquoi le vous croyant se déploie au mieux dans l'actualité historique de l'Église, comme le vous extatique d'Adam s'était déployé au contact des pures réalités intelligibles du monde divin platonisé. Dans cette actualité, le spectacle de la disparition des idoles réjouit autant le vous des chrétiens que l'exemple courageux des vierges et des martyrs, en qui se renouvelle le mystère de la passion du Christ" (Le mystère pascal du Christ selon Athanase d'Alexandrie, RSR 63(1975)407-442, p. 413s).

(344) Cf. 23, 10-28. Para convencer lo resucitó al tercer día (cf. 26, 12-35). 
En su argumentación directa contra los judíos muestra a Cristo como la realización de lo profetizado sobre él en el A. T. De un extremo a otro, cada libro divinamente inspirado proclama francamente cosas (345) como el nacimiento de una virgen, la estrella de Jacob, la ida a Egipto, el hombre de dolores que sufre por nosotros, su crucifixión, el que se levanta para mandar a las naciones (346). Ningún otro ha realizado estas cosas (347). Por si no fuera suficiente para alguno, Atanasio añade los textos de Is $65,1 \mathrm{~s}$ (encontrado por los que no lo buscaban, etc.); 35, 3-6 ( signos con ciegos, sordos, cojos y mudos). Los judíos insistirán diciendo que el ungido, Santo de los santos, todavía no ha venido. Pero chocan contra las 70 semanas de Dn 9, 24s: el reino de Jerusalén ha cesado (348), no hay profeta ni visión (349). Para confirmar Atanasio agrega la cita de Gn 49, 10 y que actualmente los paganos dan culto al Dios que dio la ley a Moisés y la promesa a Abraham (350). ¿Qué falta, entonces, por cumplir de lo que debía hacer el Cristo? (351)

Ya en la parte contra los judíos había destacado el derrumbe del reino Jerusalén, la cesación del sacrificio, y profecía, junto con la conversión de los gentiles y la derrota de la idolatría. Ahora continúa más especialmente contra los griegos, confirmando con hechos visibles a todos (352). Sigámoslo a grandes rasgos. Con la venida de Cristo los hombres han comenzado a abandonar el culto a los ídolos, los oráculos han cesado, el engaño y locura de los demonios han sido despreciados, la magia comenzó a ser pisoteada. También la sabiduría de los griegos ha enloquecido frente a la verdadera sabiduría de Dios sobre la tierra. Y Cristo es el único venerado en toda la tierra; los ídolos en cambio, cada uno en su territorio. Solo Cristo es reconocido como Dios entre los hombres. A diferencia de los sabios de Grecia, solo él con palabras simples persuadió en toda la tierra a numerosas asambleas de hombres a despreciar la muerte, a pensar en lo inmortal y elevar la vista hacia lo eterno (353). Y la verdad de esto se percibe por el testimonio de las vírgenes, de los jóvenes continentes, del coro de los mártires. El solo nombre de Cristo expulsa a los demonios, etc. ¿Quién es, pues, ese Cristo que arruina a todos los contrarios y cuya enseñanza llena la tierra? No puede ser un hombre, ni un mago, ni un demonio, sino el Hijo de Dios, el Logos, la Sabiduría y Poder del Padre. Sus obras no son humanas, sino que se reconocen ser verdaderamente de Dios, a partir de sí mismas y por comparación con las obras de los hombres (354).

¿Quién se ha formado un cuerpo a partir de solo una virgen? ¿Quién jamás ha curado tantas enfermedades? ¿Quién ha hecho ver a un ciego de nacimiento? ¿Quién ha expulsado así de los hombres las enfermedades, los demonios y la

(345) $33,11-13$.

(346) Is 7, 14 (Mt 1, 23); Nm 24, 17; Nm 24, 5-7; Is 19, 1; Os 11, 1 (Mt 2, 15); Is 53, 3-10; Dt 28, 66; Jr 11, 19; Sal 22, 17-19; Is 11, 10. También cita Is 8,4 .

(347) Cf. 33, 1-37, 59.

(348) La ciudad y el templo han sido destruidos.

(349) Hubo profecía hasta su venida, pero con la presencia de la verdad desaparece la sombra, los signos, las figuras $(40,8-14)$.

(350) Confirma la venida del Señor con Sal 117, 27; 106, 20 y Is $63,9$.

(351) Cf. 38, 1-40, 69 .

(352) $45,39 \mathrm{~s}$.

(353) Cf. 46, 1-47, 37.

(354) Cf. 48, 1-53. Respecto a la comparación, véase 15, 24-28; 43, 33s; 45, 13-16, etc. 
misma muerte? (355). A lo que se suman otros prodigios. A su muerte se oscureció el sol y tembló la tierra. Y, dejando a un lado las obras realizadas mediante su cuerpo, después de su resurrección su enseñanza, única e idéntica, se ha impuesto hasta en los confines de la tierra y su culto se extiende por todas partes. Y con su enseñanza cesa el culto de los otros (356). Nadie había logrado, ni siquiera en vida, llenar la tierra con su enseñanza y apartar tan grande multitud del culto a los ídolos. El Logos de Dios, muy paradójicamente (357), con palabras más pobres eclipsó a los sofistas, reduciendo a nada sus enseñanzas; y atrayendo a todos hacia él, ha llenado sus iglesias. Su muerte expulsó a los demonios (basta con pronunciar su nombre). ¿Quién ha despojado a los hombres de las pasiones del alma cambiándolos así? Persuadió a los bárbaros a abandonar su locura y tener pensamientos de paz. Con su cruz y resurrección garantizó a los hombres la inmortalidad (358).

Hasta niños profesan la virginidad enseñada por Cristo. Mediante sus discípulos ha predicado la virtud, la temperancia, y contra los ídolos; a los bárbaros de diversos sitios ha persuadido en su mente a cambiar de costumbres, a reconocerlo a él y por su medio adorar al Padre. Estos, al escuchar sus enseñanzas se tornan en pacíficos agricultores y triunfan sobre los demonios con la temperancia y la virtud. Esto es un signo de la divinidad del Salvador. Así los discípulos de Cristo, entre otras cosas, desprecian la muerte y se convierten en mártires de Cristo (359). Signo del todo maravilloso de la divinidad del Salvador es que lucha solo, con un mismo impulso, contra toda la idolatría, todo el ejército de los demonios, toda la magia y toda la sabiduría de los griegos, tan floreciente y admirada, refutando invisiblemente el error de cada uno y despojándolos a todos. Así pisotean los ídolos, queman los libros mágicos y los sabios prefieren la interpretación de los evangelios. Adoran al crucificado, del que se reían, confesándolo Dios y proclamándolo en toda la tierra. Reciben la enseñanza de Cristo y llevan una vida más temperada. Estas son obras de Dios y no humanas (360).

Y Atanasio, al concluir, dice que las buenas acciones ( $\kappa \alpha \tau \rho \rho \theta \omega \mu \alpha \tau \alpha)$ del Salvador mediante su encarnación (361), son incontables como las olas del mar, son prodigios y a donde uno dirija la vista queda estupefacto viendo la divinidad del Logos (362). Con la venida del Salvador disminuye la idolatría y poco a poco cesa, la sabiduría de los griegos tiende a desaparecer, y los demonios ya no engañan con sus fantasmagorías, oráculos y magia, sino que son confundidos con el signo de la cruz (363). Y por todas partes crece la enseñanza del Salvador. Contemplando esto, adora, pues, al Salvador y poderoso Dios Logos, que como el sol expulsa las tinie-

(355) Ha enseñado temperancia.

(356) 49, 1-34.

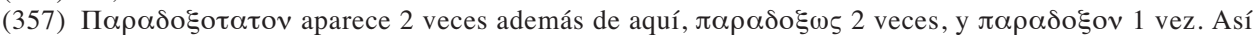
es calificado el que el Logos está en un cuerpo y mueve el universo $(17,4)$, el recibir una muerte ignominiosa que se convierte en trofeo contra la muerte $(24,27)$, el morir y no corromperse sino destruir la muerte $(20,35)$. El cambio en el hombre producido por Cristo también es llamado 2 veces paradójico $(28,6 \mathrm{~s} ; 51,32)$.

(358) Cf. 50, 1-41. Por la resurrección puede ser conocido como Hijo de Dios.

(359) Cf. 51, 1-52, 34.

(360) Cf. 53, 1-33.

(361) En su cuerpo.

(362) 54, 21-35.

(363) Tema a menudo repetido. 
blas. Todo esto constituye una señal de que Cristo es Dios Logos, Poder de Dios e Hijo unigénito (364).

En resumen, el Logos invisible se hace conocer por sus obras y mediante él tenemos una idea del Padre. Sus obras llenan todo el escrito de Atanasio. Vistas antes las obras de la creación y las por su cuerpo, aunque ambas a ratos se entreveran con las actuales (después de la resurrección) formando una sola unidad 'esplendorosa', en esta parte nos dedicamos a lo que nos aporta la polémica directa contra los judíos y griegos desde el número 33 en adelante. Salvo el cumplir numerosas profecías, todo lo demás ya estaba dicho antes en general y ahora es largamente repetido. Es la victoria de la enseñanza de Cristo, que llena la tierra, contra la idolatría, los demonios, la sabiduría de los griegos. La cruz es el trofeo de la victoria. Cristo es el que cumple las profecías, habiendo cesado entre los judíos el reino, la profecía y el sacrificio. A ratos sus expresiones retóricas parecen ya haber terminado con todos los enemigos, pero en su conclusión vuelve a dejar en claro que esto es lo que está sucediendo en el presente (365). En este tratado apologético pesa, pues, fuertemente el triunfo de Cristo en el tiempo de Atanasio. Todo muestra con diafanidad la divinidad de Cristo.

\section{CONCLUSIÓN}

Si en el CG el Logos es muy central, en el DI es el Logos en un cuerpo (366). Primeramente lo vimos en su relación al Padre y después como Creador. Pero el centro de la obra es la Encarnación por filantropía, y sus causas. La Encarnación, saltándose el alma, está dicha como la manifestación del Logos en un cuerpo. El cuerpo del Logos es lo fundamental para nuestra salvación, porque es lo semejante a nosotros y por ese cuerpo individual la salvación nos alcanza a todos. En su muerte, que paga la deuda (deroga la ley), todos morimos. En su resurrección la vida desplaza a la muerte y el cuerpo obtiene la inmortalidad e incorruptibilidad. Él es primicia de los resucitados. Además, en Cristo ha quedado rehecho el hombre según la imagen, porque el Logos, que es la imagen del Padre, está en un cuerpo. En resumen, vencer a la muerte por la cruz (razón principal) y rehacer la imagen son las dos causas de la Encarnación, que, por lo demás, están mutuamente relacionadas. Si Atanasio solo repite que la imagen ha sido rehecha, sin profundizar, es en parte porque no se lo permite el haberse saltado el alma de Cristo. La salvación, pues, es

(364) Cf. 55, 1-44.

(365) "Ma ormai esso è stato definitivamente vinto, e la prova di ciò è che esso dopo la venuta di Cristo non si è più sviluppato, anzi è evidentemente in via di estinzione. Perciò egli può già considerare l'idolatria e la corruzione, sua compagna, come un $\pi \alpha \lambda \alpha$, al quale vivacemente oppone il $v v v$ della nuova 'divinizzante' (DI 54, 11s) realtà cristiana” (De Nicola, op, cit, 105s).

(366) Así concluye De Nicola su estudio (op. cit., 106): "Conseguentemente tutta la concezione storica atanasiana nelle sue parti, quelle della creazione e caduta dell'uomo e quella della sua redenzione, ha un solo significato, quello teologico inteso a mostrare l'assoluta centralità del Logos. La creazione è stata fatta per suo mezzo, la caduta esige, a modo suo, che Egli misericodiosamente intervenga, e l'Incarnazione ricrea e riplasma la nuova umanità destinata a ricuperare alla fine del tempo l'incorruttibilità originaria. In tal modo il fine voluto da Dio Padre nella creazione dell'uomo raggiunge, per mezzo del Logos, la sua realizzazione". 
por el cuerpo (instrumento) del Logos. Por tanto el conocimiento de Dios (muy importante en una obra 'apologética'), que forma una unidad con el tema de la imagen, ya no es prácticamente por el alma en su pureza de imagen, como destacaba el CG, sino por las obras visibles del Logos. Y como el hombre no mira hacia el cielo, donde resplandece el orden de la creación, es por las obras sensibles del cuerpo de Cristo, que incluyen también su muerte y resurrección y por las que ahora el resucitado (invisible) sigue realizando a vista de todos en la transformación de los hombres en toda la tierra, derrotada la idolatría, los demonios y la sabiduría de los griegos, terminado el reino, el sacrificio y la profecía entre los judíos.

Notemos que el Logos como tal, nunca ha sido visto sino a través de sus obras. Aunque las obras del Logos 'encorporizado' son contrastadas con las de la creación (del mismo Logos), todas conforman una sola unidad que muestra esplendorosamente su divinidad, la de Cristo. Y por el Logos llegamos a una idea de Dios el Padre, quien se deja ver poco en nuestra salvación, salvo en su bondadosa decisión de salvarnos mediante el mismo por quien nos había creado y en el gran tema del conocimiento de Dios, porque el Hijo es quien nos enseña al Padre y a través del cual lo conocemos. El Espíritu Santo solo aparece en una doxología final. Diríamos que su papel está absorbido por el Logos. La relación de Cristo al Padre, salvo el darlo a conocer, aparece muy poco. El Logos obviamente es el Hijo unigénito del Padre, su Logos, Sabiduría y Poder, viene del Padre ( $\varepsilon \kappa)$. Dios, el Padre, por así decirlo, se relaciona con el cosmos por su Logos. El Hijo es el Señor, el rey, el $\delta \varepsilon \sigma \tau o \tau \eta \zeta$, el Salvador, la vida, los $\alpha v \tau$-, etc. (367). Así, no se dice que el Padre esté en el cosmos (368). Es el Logos el que está en todas partes y todo lo llena. El Logos está en su propio cuerpo (el de Cristo), en el universo, pero entero solo en el Padre, en quien descansa. El Logos es trascendente al universo, lo contiene, pero no es contenido por este; no participa del cosmos sino que el cosmos participa de él. El Logos es esplendoroso como el sol que expulsa las tinieblas. Así como ilumina, vivifica y mueve el cosmos, así su propio cuerpo. Parece desplazar el alma de Cristo. Tampoco Atanasio necesita su alma para explicar la redención. Y nosotros los hombres, si recuperamos la imagen, somos los 'lógicos', tenemos la vida según Dios, somos divinizados. El Logos es la imagen del Padre, nosotros somos según la imagen.

Lo que nuestro autor destaca más es la victoria sobre la muerte por la cruz, y las obras que lo dan a conocer. En esto es muy importante el cuerpo. Ha expuesto una gran teología del Logos. En general da por supuesta la existencia de Dios y la de su Logos a partir de la creación. La creación va apareciendo en diversas sitios, en parte porque la salvación es un recrear (restauración), y tiene que ser realizada por el mismo que había creado. Así Atanasio ha expuesto la racionalidad de la Encarnación para un creyente refutando las objeciones de griegos y judíos, y con un gran despliegue de los hechos maravillosos y divinos. La racionalidad de la Encarnación va junto con la afirmación de la divinidad del Logos.

(367) La $\pi \rho o v o \iota \alpha$ es del Logos.

(368) Está en Cristo y Cristo en él (18, 16s citando Jn 10, 38). 


\title{
RESUMEN
}

El autor, apoyado en el uso de múltiples vocablos, nos ofrece una aproximación al Logos en el De incarnatione Verbi de Atanasio, sin descuidar su conexión con el Contra Gentes. Las dos causas principales de la Encarnación son: la victoria sobre la muerte y la reconstitución del hombre según la imagen. Respecto a la primera, además del pago sacrificial de la deuda, destaca sobre todo que la vida desplaza a la muerte, que estaba entrelazada con el cuerpo, porque el Logos es la $\alpha v \tau o \zeta \omega \eta$. El cuerpo de Cristo pasa de incorruptible a inmortal en la resurrección, lo que se extiende a todos, dada la semejanza del cuerpo del Logos con el nuestro. Respecto a la segunda causa, el hombre es reconstruido según la imagen, porque en el cuerpo de Cristo está la misma imagen del Padre, que es el Logos, quien, mediante sus obras, nos vuelve a enseñar sobre el Padre. Porque ser según la imagen, $\lambda$ oүıкоı, es conocer a Dios. Estas obras del Logos encarnado incluyen, en buena medida, la derrota de los griegos idolátricos, y del judaísmo que tenía la promesa, por el cristianismo. Atanasio nos presenta, pues, una esplendorosa teología del Logos Dios, creador (providente) y salvador, pero pasa en silencio el alma de Jesús.

\begin{abstract}
The author of this article, supported by the utilization of multiple terms, offers us an approximation to the concept of Logos in De incarnatione Verbi of Athanasius, without discarding its connection with Contra Gentes. The two principal causes of the Incarnation are: the victory over death, and the reconstitution of man according the image.

Regarding the first, apart from the sacrificial payment of debt, it highlights above all the fact that life displaces death, which was interlinked with the body, because the Logos is the $\alpha v \tau o \xi \omega \eta$. The body of Christ passes from the incorruptible to the immortal in the Resurrection, which extends to all, given the similarity of the body of the Logos to our own.

Regarding the second cause, man is reconstructed according to the image, because in the body of Christ is the same image of the Father, which is the Logos, who, through his works, teaches us again about the Father, because to be according to the image, $\lambda$ oүıко, is to know God. These works of the incarnate Logos include, in good measure, the downfall of the idolatrous Greeks, of Judaism which had the promise, through Christianity. Athanasius presents us, therefore, with a splendid theology of the Logos-God, (providential) creator and savior, but passes over in silence the soul of Jesus.
\end{abstract}


